Discussion

Papers

Global Futures of Energy, Climate, and Policy

Qualitative and Quantitative Foresight towards 2055 
Opinions expressed in this paper are those of the author(s) and do not necessarily reflect views of the institute.

IMPRESSUM

(C) DIW Berlin, 2019

DIW Berlin

German Institute for Economic Research

Mohrenstr. 58

10117 Berlin

Tel. +49 (30) $89789-0$

Fax +49 (30) $89789-200$

http://www.diw.de

ISSN electronic edition 1619-4535

Papers can be downloaded free of charge from the DIW Berlin website:

http://www.diw.de/discussionpapers

Discussion Papers of DIW Berlin are indexed in RePEc and SSRN:

http://ideas.repec.org/s/diw/diwwpp.html

http://www.ssrn.com/link/DIW-Berlin-German-Inst-Econ-Res.html 


\title{
Global Futures of Energy, Climate, and Policy: \\ Qualitative and Quantitative Foresight Towards 2055
}

\author{
Dawud Ansari ${ }^{a, b}{ }^{*}$, Franziska Holz ${ }^{a}$, Hasan Basri Tosun ${ }^{c, d}$ \\ ${ }^{a}$ German Institute for Economic Research (DIW Berlin), Mohrenstr. 58, 10117 Berlin, Germany \\ ${ }^{b}$ Energy Access and Development Program (EADP), Pflügerstr. 18, 12047, Berlin, Germany \\ ${ }^{c}$ Middle East Technical University (METU), Üniversiteler Mh., Eskişehir Yolu No:1, 06800 \\ Çankaya/Ankara, Turkey \\ d Sensgreen, Üniversiteler Mahallesi, İhsan Doğramacı Bulvarı, ODTÜ Teknokent No:13, Kuluçka \\ Binası, Çankaya / Ankara \\ *Corresponding author: dansari@diw.de
}

\begin{abstract}
:
Existing long-term energy and climate scenarios are typically a rather simple extrapolation of past trends. Both qualitative and quantitative outlooks co-exist, but they often focus narrowly on individual perspectives, which is opposed to the interlinked and complex nature of energy and climate. Therefore, this study presents a set of novel and multidisciplinary narratives that give insight into four distinct and extreme yet plausible worlds: base case 'Business-as-usual', worst case 'Survival of the Fittest', best case 'Green Cooperation', and surprise scenario 'ClimateTech'. Going beyond other outlooks, our narratives focus on changes in the geopolitical landscape and global order, social perspectives on climate issues, and technological progress. These holistic scenarios are designed to overcome previous barriers by an innovative bridging between both qualitative and quantitative methods. We start with the generation of qualitative scenario storylines using techniques of foresight analysis, including a facilitated expert workshop. Then, we calibrate the numerical energy systems model Multimod to reflect the different storylines. Finally, we unite and refine storylines and numerical model results into holistic narratives.

In addition to the narratives (which include quantitative results on e.g. emissions, energy consumption, and the electricity mix), the study generates insights on the key uncertainties and drivers of different pathways of (more or less successful) climate change mitigation. Additionally, a set of transparent indicators serves as an early-warning system to identify which of the paths the world might enter. Lessons learnt include the dangers from increased isolationism and the importance of integrating economic and energy-related objectives as well as the large role of public opinion and social transition.
\end{abstract}

Keywords: Energy and climate; scenarios; equilibrium model; global order; geopolitics

JEL: C61, C73, D78, F50, L13, Q40, Q47, Q54, Z13 


\section{Acknowledgements}

We thank Oliver Gnad, Nathan Appleman, Hashem al-Kuhlani, Ezaldeen Aref, Ruud Egging, Daniel Huppmann, Sauleh Siddiqui, Christian von Hirschhausen, Claudia Kemfert, Jimi Oke, Konstantin Löffler, Thorsten Burandt, Isabell Braunger and Gustav Resch for their helpful comments on earlier versions of the manuscript. We are indebted to the participants of the DIW Berlin Scenario Foresight Workshop in November 2016 and the TU Berlin Scenario Workshop in April 2018. Also, we thank for comments at the Berlin Conference on Energy and Electricity Economics 2017 and 2018 (Berlin, Germany), the IHS and ÖGOR workshop Mathematical Economics and Optimisation in Energy Economics 2018 (Vienna, Austria), the Transatlantic Infraday 2018 (Washington DC, USA), and the $41^{\text {st }}$ IAEE International Conference 2018 (Groningen, Netherlands).

The project has received funding from the European Union's Horizon 2020 research and innovation programme under grant agreement no. 691843 (SET-Nav). 


\section{Introduction}

Recent years have again seen the global energy system marked by rapidly changing trends. Between the rapid expansion of shale oil and gas in North America, the phase-out of nuclear energy in parts of Europe, the drop in global oil prices, and the Paris Agreement, the need to understand the underlying inter-linkages is apparent. Outlooks help to differentiate relevant signals from 'noise' and to identify the impact of today's emerging trends.

Ways between different kinds of outlooks part when it comes to choosing either a qualitative or a quantitative approach. Qualitative methods, on the one hand, allow for the inclusion of a wide range of possibilities and factors but fail to estimate the system-wide consequences and lack the precision of numerical results. Quantitative methods, on the other hand, deliver consistent and precise results, but they are inherently bound by the assumptions and rules of the underlying model, which is why they can rarely go beyond linear progressions of the present.

This study presents the methods and results of a qualitative and quantitative scenario building study for the global energy system towards 2050. Our four narratives (base case 'Business as usual', worst case 'Survival of the Fittest', best case 'Green Cooperation', and surprise scenario 'ClimateTech') describe distinct and extreme yet plausible worlds which bring insights for understanding if and how emerging trends today may be signals of forthcoming threats and opportunities. The narratives do not attempt to predict the state of the global energy system by the year 2055, but they rather give bounds to the range of plausible alternative futures by defining certain trajectories, downside risks, and new trends that could significantly affect developments in the years to come.

We use this approach to shed light on dimensions that are typically side-lined by numerical energy outlooks: changes to the global political order and geopolitics, social aspects of climate objectives, and resulting technological pathways. The international governance system is both driver and result of developments. Climate policy, in particular, is a major determinant of the future energy system, but it competes with other political objectives and its political and social perception may vary with the surrounding and between different levels of governance. Investors have an essential impact on trajectories, as innovation, learning effects, and cost reductions depend on them. This imbroglio may seem to consolidate system inertia and path dependency, but the mutual enforcement of (new) trends can also create the space for deviations from known trajectories.

Our paper bridges between qualitative and quantitative approaches in the following sense. Our final narratives are the result of a three-step process. First, storylines and their underlying parameters (drivers, uncertainties, megatrends) are established in a scenario foresight exercise à la [1]. Secondly, we extract key parameters from the storylines and feed them into the global multi-fuel, multi-sector, numerical energy systems model Multimod [2]. Lastly, we integrate qualitative storylines and quantitative model results to obtain holistic narratives that project energy and climate trajectories but consider societal, political, security, and technological aspects alike.

Discussions regarding the integration of concepts and methods are not new: [3] calls for the understanding of the energy system as an integrated socio-economic system. Exogenous factors such as politics steer the energy system via technological change [4] or governance capabilities [5]. Neglecting social aspects in outlooks, for instance, produces overestimations of the feasible action space [6], and increased conservatism from missing interdisciplinary feedbacks in models may actually harm the energy transition [7]. Therefore, approaches that refrain from crossing disciplinary borders could be unsuitable to assess energy futures whatsoever [8]. A stronger inclusion of qualitative methods may be the only way to incorporate multiple major dimensions of uncertainty [9], but the eventual extent to which qualitative and quantitative methods can be combined is controversial [10-12].

Previous examples for the integration of quantitative modelling with qualitative foresight in energy (of varying extent, depth, and methods) include regional energy systems [13-15], hydrogen energy 
[16], transport energy demand [17], numerically-looser climate issues [18, 19], and discussions for similar sectors such as land use [20]. Other processes of deriving holistic scenarios in the sense of this study are envisageable (e.g. [21-23]).

Our study provides vital insights into the future developments that are of interest for both academia and policy. First, our narratives give precise insight into four holistically designed, possible futures of energy, climate, and its surrounding world, including numbers for key variables of the energy system. In the sense of [24], the narratives benefit future-exploring sailors and data-oriented divers equally. Secondly, the study manifests the deep interlinkages between different spheres, which gives rise to new considerations for both research and policy design. Thirdly, we provide a set of diagnostic indicators that provide a transparent early-warning system which path the world might be entering. 


\section{Methods}

We apply a mix of qualitative and quantitative analyses to construct four distinct, fully-fledged storylines of global energy and societal developments until 2055. We aim at going beyond a "simple" extrapolation of the past with a continuation of current trends, as we did in earlier work (e.g. [25]). Our storylines represent four rather extreme yet plausible developments of the medium term (i.e. the next decade) and long term (beyond 2030, to 2055). Clearly, short- and medium-term decisions will determine the long-term pathways. We therefore distinguish these two time stages in the narratives presented in Section 3.

We use qualitative and quantitative methods sequentially (Figure 1). First, we develop qualitative storylines using scenario planning (also called scenario foresight). Second, we use parameters derived from the qualitative storylines in the numerical energy and resource market model Multimod to quantify the energy and climate aspects of the storylines. Third, we integrate the quantitative model results with the storylines to obtain comprehensive, fully-fledged narratives that describe energy and climate but also consider the societal, political, security and technology aspects.

In all steps, we distinguish regionally-different developments, at least on continental level. While in some scenarios, the developments may be shared across regions (e.g. a push towards renewables), there may be conflicting developments in other scenarios with ambiguous aggregate effects on the global climate. It is therefore of prime importance to look at the different regions individually and also at their interaction.

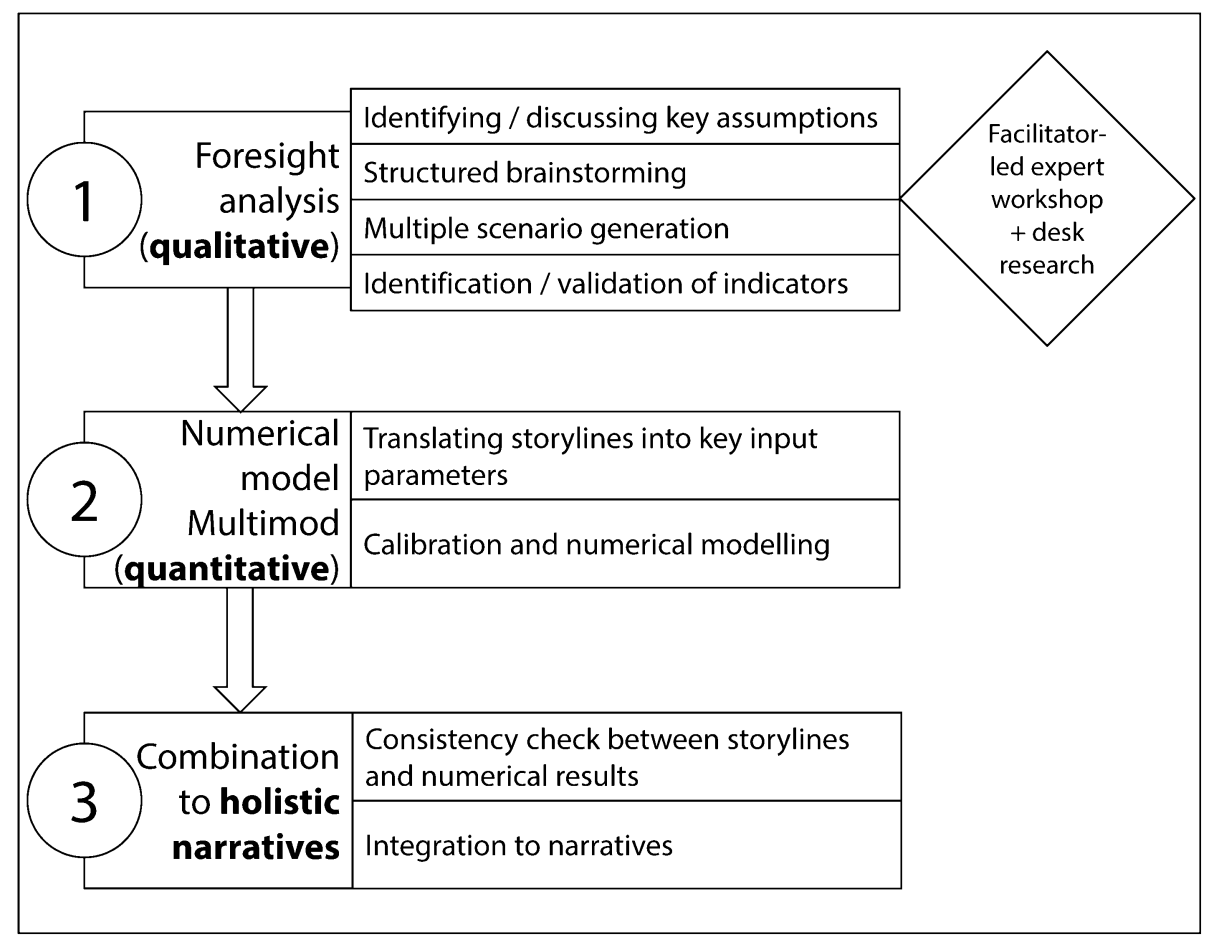

Figure 1: Illustration of our three-step method to reach holistic narratives

\subsection{Qualitative analysis: Scenario foresight}

In the first step, we develop qualitative storylines that encompass broad societal developments until 2055. We aim at integrating some unexpected developments or events (e.g., so-called "Black Swans") in our scenarios. We therefore use the complex scenario planning method, also called scenario foresight. This is distinct from a "forecast" method as employed, for example, for business cycle outlooks, which provide bounded statements about future events and conditions in the short (or mid) run. Foresight is also different from "predictions", which are definitive statements about what will occur in the future. Rather, we develop and use scenarios in sense of "exploring different possible 
futures, the levers that bring them about and the interactions that arise across a complex [....] system" [26, p. 23]. Foresight analysis helps us in this exploratory analysis because it is in itself a "reframing process" that involves exploiting insights to thinking about the future [1, p. 14].

We aim at providing comprehensive scenarios that encompass the complexity of human systems by working in the STEMPLE+ analytical framework. STEMPLE+ describes the areas included in our foresight considerations: social, technological, economic, military/security, political, legal, environmental, plus others (e.g., cultural, psychological).

We follow the method of [1], which relies to a large extent on [27] and [28]. ${ }^{1}$ This method involves a four-step foresight process. In our foresight process, we have mixed desk research with group work in a "scenario workshop". Participants in the scenario workshop were approx. 30 experts from different areas in energy, climate, and economics and active in academia, media, public sector, and industry ${ }^{2}$. The following four steps in the process can be distinguished: ${ }^{3}$

1) Identifying and discussing key assumptions: This step was done by both the authors and the workshop participants prior to the workshop (identifying key assumptions) and during the first part of the workshop (discussing key assumptions). Key assumptions are commonly accepted assumptions about major future developments ("truisms", [1, p. 13], also see Table 1). This step served for workshop participants to clarify which assumptions they were unlikely to challenge in the remainder of the foresight process.

2) Structured brainstorming on the research question in the STEMPLE+ analytical framework: The research question given to the workshop participants was "What are the drivers of the renewable energy transition until 2050?" Preparatory brainstorming was done by the workshop participants individually prior to the workshop in an online survey. The main part of this exercise took place in group discussions and under moderation (see [1] for more details). Brainstorming results of relevant drivers were clustered in "affinity groups", potentially ignoring outliers. Thereby, key drivers were obtained which are critical influence factors that may eventually change the entire system. ${ }^{4}$ The workshop groups selected some main key drivers that are mutually exclusive, i.e. that are exerting influence in a very particular direction.

3) Multiple scenario generation: In this step, storylines of plausible alternative futures were developed by the groups during the workshop. First, simple alternative futures were analysed by the workshop groups by combining two key drivers (that are logically consistent with each other) and identifying their extreme (e.g. best and worst case) developments. Hence, for each combination of two key drivers, a $2 \times 2$ matrix with four simple, mutually exclusive storylines was obtained in which it was ensured that proportional consideration was given to each of the two defining drivers. Each of the four storylines was described by a telling title, some main characteristics as well as a brief analysis of the consequences of the future world described. Second, after the workshop, all outstanding storylines ("best case", "worst case", "surprise scenarios") were selected. Third, the selected storylines were grouped together by themes such as to obtain complex (comprehensive) "raw narratives" that include a chronology of events, rather precise explanations of factors and drivers, actors and trends, as well as a precise description of the final state in each scenario (by 2055, in our study). These "raw narratives" were the core of our final narratives presented in Section 3 where they are enriched and specified by our quantitative model results.

\footnotetext{
1 Oliver Gnad was the moderator and facilitator of the scenario workshop in November 2016 that we refer to.

${ }^{2}$ Unfortunately, the diversity of the group was limited however: Only four participants were female, and only two participants originated from the Global South. Moreover, public sector affiliates were advisory personnel, but no direct decision-makers participated.

${ }^{3}$ More detail on the course of the workshop and its intermediate results can be found in the Appendix of [29] D. Ansari, F. Holz, N. Appleman, SET-Nav Case Study Report: Scenarios of the global fossil fuel markets, 2018.

${ }^{4}$ For example, digitalization, climate change and demographic change (i.e., aging societies) are such key drivers that influence the economic and energy system around the globe.
} 
4) Identification and validation of indicators5: For each scenario, "early warning" signals were identified which help detect which scenario unfolds in the real world. Based on [1] and [27], each scenario is underpinned by a set of distinct ("diagnostic" [27, p. 135]) indicators: some observable phenomena that, for example, help to notice emerging trends and to "separate relevant information from noise" [1, p. 15]. In addition, to their unique "diagnostic" character, indicators must be observable and collectible, valid, reliable, and stable over time [27].

The group work with a rather heterogeneous group allowed overcoming cognitive limitations and biases of individual analysts, in particular the tendency to think only about known phenomena. As a result of this workshop method and the group brainstorming exercises, each of the four final scenarios takes a particular focus. More concretely, we continue to work with the scenarios Business as Usual, Survival of the Fittest, Green Democracy, and Climate Tech. ${ }^{6}$ In Section 3, we present the key assumptions and key uncertainties identified in first step of the foresight process as well as the comprehensive narratives and the indicators for each scenario.

\subsection{Quantitative analysis: Multimod}

The second step in our analysis, we quantify the scenario trajectories defined by the foresight analysis. For this purpose, we use the energy and resource market model Multimod. It has a global focus and includes different fuels with multiple value-chain steps and differentiated demand sectors. Unique features include imperfect competition as well as endogenous investments and fuel substitution. Multimod itself is also of hybrid nature in the sense that it bridges ${ }^{7}$ between partialequilibrium modelling (to account for strategic actions and infrastructure detail) and the broad scope of an energy system model (global scale and interdependencies). Different forms of the model,

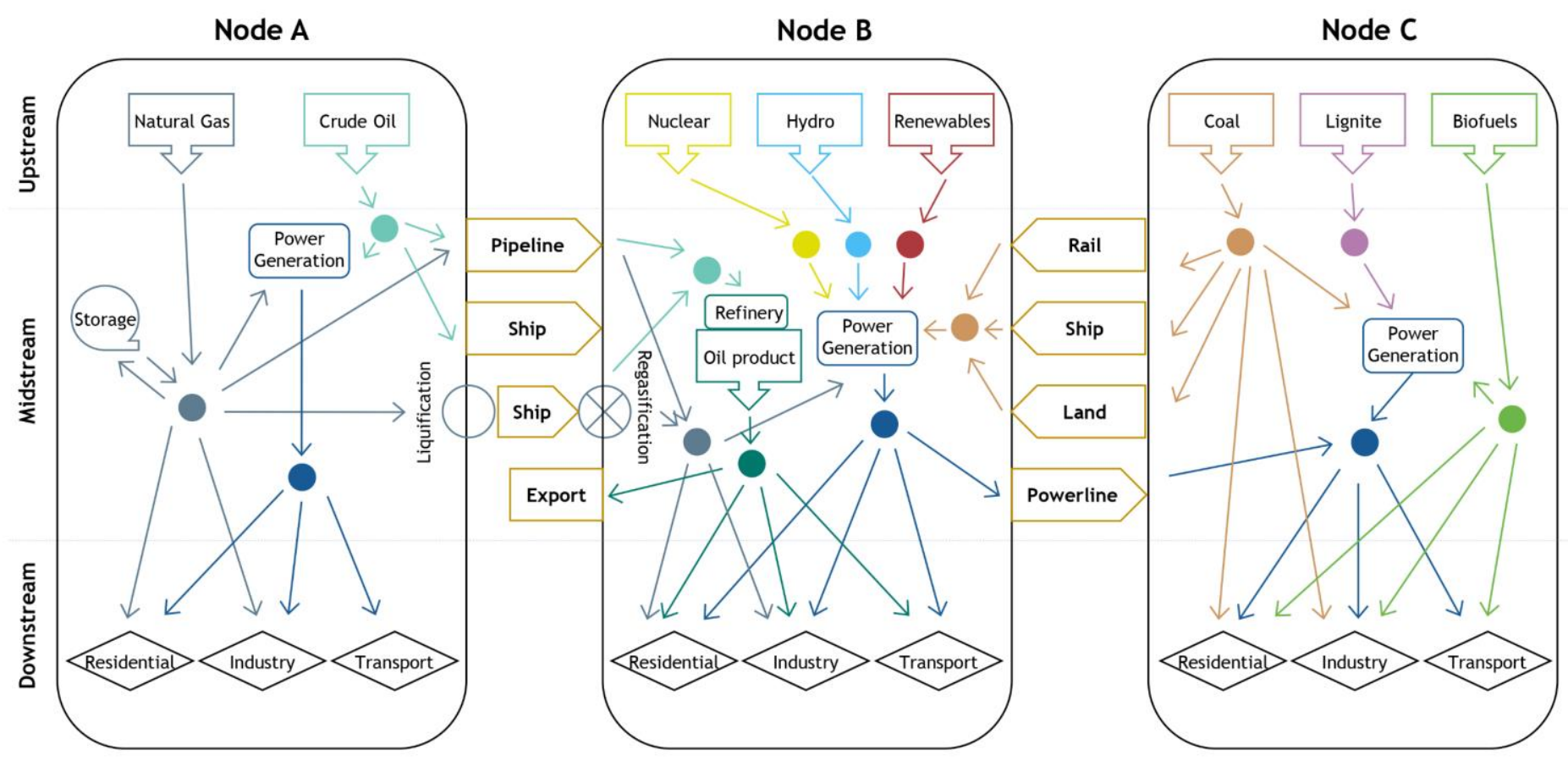

Figure 2: Illustration of the value chain in Multimod

\footnotetext{
${ }^{5}$ The indicators are listed in Appendix A.

6 We re-named the scenario "Green Democracy" to "Green Cooperation" when adding the quantitative scenario characteristics to emphasize the broader scope of the scenario.

${ }^{7}$ While a broad research scope requires substantial aggregation but necessarily omits many details, central topics in energy such as infrastructure investments require sufficient detail. Each energy model weighs this trade-off differently by setting different priorities and levels of granularity in addition to the choice of endogenous (i.e. model output) and exogenous (i.e. model input) variables.
} 


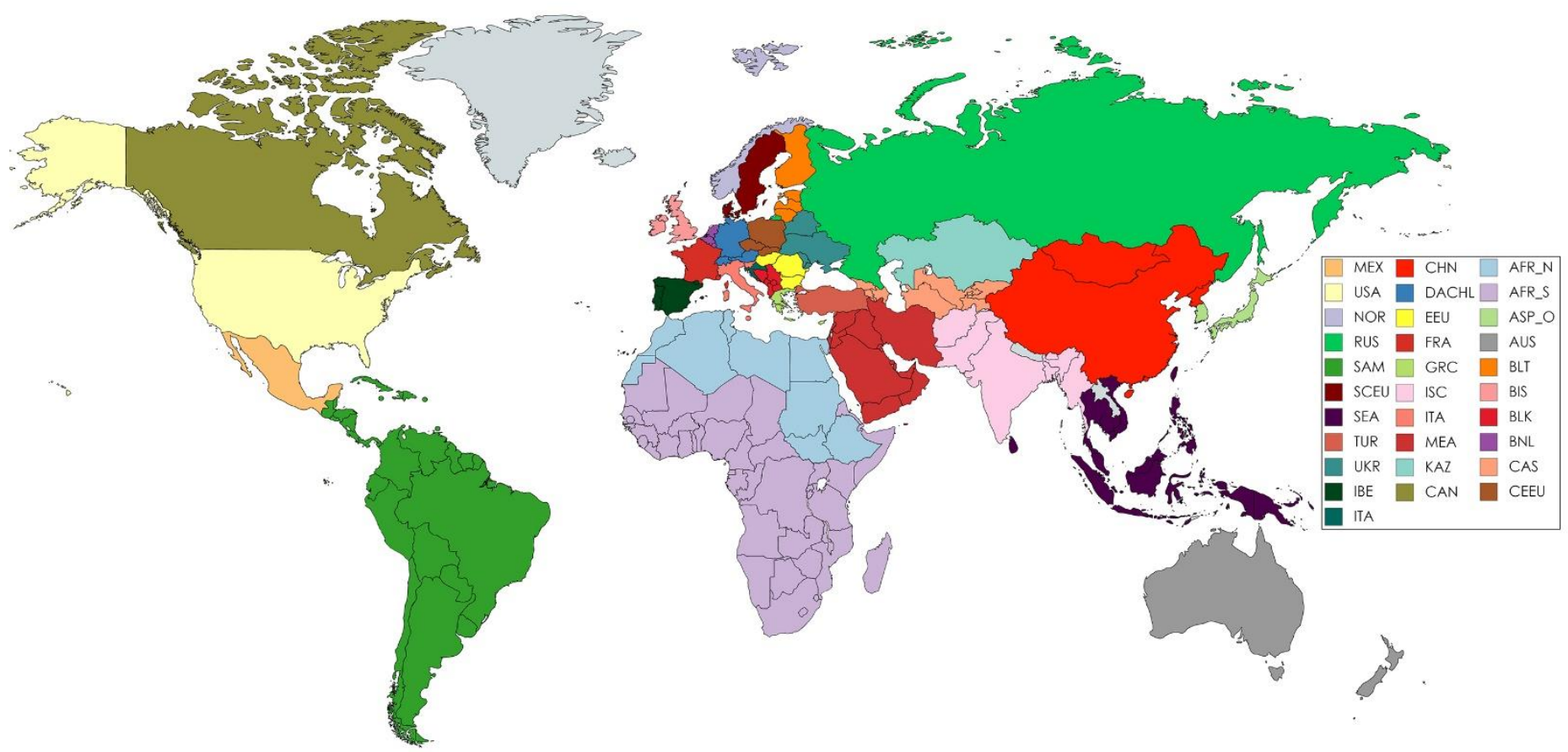

Figure 3: Illustration of the nodes defined in the numerical data set

initially developed and elaborated by [2], have been used by recent studies, e.g. of the global energy system [2] as well as North-American crude oil [30, 31] and natural gas markets [32, 33].

The model is adapted and calibrated to express the settings of each scenario. This includes variations of production and transportation costs, technology availability and efficiency, as well as the availability of certain transport routes and reference demand parameters. As a result, we obtain key variables (energy production and consumption, $\mathrm{CO}_{2}$ emissions, infrastructure investment) that match the setting of the storylines. Main data sources ${ }^{8}$ include the World Energy Balances [34], 2016's MIT Food, Water, Energy \& Climate Outlook [35-37], and recent scientific publications (e.g. [38-40]).

Multimod reflects the complex, non-linear and interrelated reality of energy infrastructure. ${ }^{9}$ The model covers multiple periods of planning and system operations. Here, the model proceeds in tenyear-steps from 2015 to 2055. It disaggregates the globe into nodes, which represent geographic entities (30 distinct nodes in this study, as illustrated by Figure 3). These nodes are home to the different actors along the energy value chain (Figure 2), i.e. suppliers (upstream), energy service providers (midstream), and retailing (downstream). Our version of the model covers natural gas, coal, lignite, and crude oil on the fossil fuel side as well as hydro, biofuels, other renewables (solar / wind / geothermal), and nuclear energy on the upstream level. While some of these fuels can be used directly, others will need to be processed first, or they can be transported via various modes (ship, pipeline, rail, street, power line). The setup includes energy storage as well as natural gas liquefaction and LNG regasification. Certain producers - here, a limited number of oil and gas producers (OPEC members, Qatar, Russia) - can exercise market power in a Cournot fashion, i.e. they choose their supply strategically. The model distinguishes three separate and individual demand sectors (residential, industrial, transportation), which are represented by an own demand in each node of the model. Emissions are computed for each action (production, service, and consumption of specific fuels) along the supply chain.

As an equilibrium model, Multimod assumes that the different actors aim at optimising a certain objective: While producers of energy and service providers aim at maximising their profits, final

\footnotetext{
${ }^{8}$ More background on data and parameters is given in Appendix $C$.

${ }^{9}$ Appendix $B$ contains a more technical description of the model as well as its equations.
} 
consumers are utility-maximisers. This allows for the derivation of optimality conditions, i.e. equations that represent the actors' sets of optimal choices. The outcome of the system as a whole is obtained at the intersection of these optimality conditions, such that all actors take the best possible decision to realise their objectives, given all others' actions - an equilibrium. 


\section{Four Scenarios}

As a result of the qualitative scenario foresight exercise, we obtain four distinct (raw) storylines of very different future worlds (Section 2.1). These four storylines are quantified by Multimod (Section 2.2). In this section, we present the final narratives - Business as Usual (reference case), Survival of the Fittest (worst case), Green Cooperation (best case), and ClimateTech (surprise scenario) - that are obtained from the combination of qualitative and quantitative scenario work.

The scenario foresight method gives a structured framework for defining and analysing alternative futures. We use its tools also to describe and analyse our quantitatively enriched narratives. In particular, we define the key assumptions and mega-trends (Table 1) as well as the key drivers and uncertainties (Table 2) as they are relevant for all scenarios. Moreover, for each of the scenarios, we identify the diagnostic indicators (Appendix A). Figure 4 illustrates the timelines and main events of the four narratives.

We highlight some major regional developments and, more importantly, give a chronological account of the global developments towards 2055. For each narrative, we provide a detailed description as well as central numbers of the global energy system (primary energy production, final energy consumption, and the electricity mix). A comparative overview (including the trajectories of emissions, fossil fuels, and renewables) is given in Section 4.

Table 1: Megatrends, key assumptions, and key uncertainties

\begin{tabular}{|l|l|}
\hline \multicolumn{2}{|c|}{ Megatrends and key assumptions } \\
\hline $\begin{array}{l}\text { Population } \\
\text { growth and } \\
\text { urbanisation }\end{array}$ & $\begin{array}{l}\text { Despite shrinking fertility rates in many industrialised countries, the world } \\
\text { and especially the Global South continue to see large rates of population } \\
\text { growth and urbanisation. Although the pace may decrease in the decades to } \\
\text { come, the world will move closer towards the milestone of 10 billion } \\
\text { humans. }\end{array}$ \\
\hline $\begin{array}{l}\text { Over the last decades, energy technologies - especially renewables but also } \\
\text { others - have observed more-or-less-sharp cost decreases. Although the } \\
\text { gradient of future cost development and the distribution across } \\
\text { technologies depends on various factors, cost declines will continue. }\end{array}$ \\
\hline $\begin{array}{l}\text { Fossil fuel } \\
\text { availability }\end{array}$ & $\begin{array}{l}\text { Reserves of fossil energy carriers remain high despite ongoing extraction. } \\
\text { Current production levels can be maintained for more than a century. } \\
\text { Therefore, supply-induced production peaks over the course of the scenario } \\
\text { outlooks are improbable. }\end{array}$ \\
\hline $\begin{array}{l}\text { Economic } \\
\text { integration }\end{array}$ & $\begin{array}{l}\text { The global economy is deeply interconnected on various levels, including } \\
\text { both virtual layers (e.g. banking) and physical layers (e.g. trade, multinational } \\
\text { supply chains). Trade barriers and protectionist policies may affect the } \\
\text { extent of economic interlinkage, but the overall integration is unalterable. }\end{array}$ \\
\hline \multicolumn{2}{|c|}{ Key uncertainties } \\
\hline $\begin{array}{l}\text { Which stance will local, national, and international actors have on climate change mitigation? } \\
\text { Which policies will result from this? }\end{array}$ \\
\hline How will the various geopolitical conflicts and tensions develop? \\
\hline $\begin{array}{l}\text { Will there be an integration towards global governance or will isolationism provide an end to } \\
\text { political globalisation? }\end{array}$ \\
\hline $\begin{array}{l}\text { How will energy and climate technology portfolios develop as a result of (dis-)incentives for } \\
\text { investors? }\end{array}$
\end{tabular}




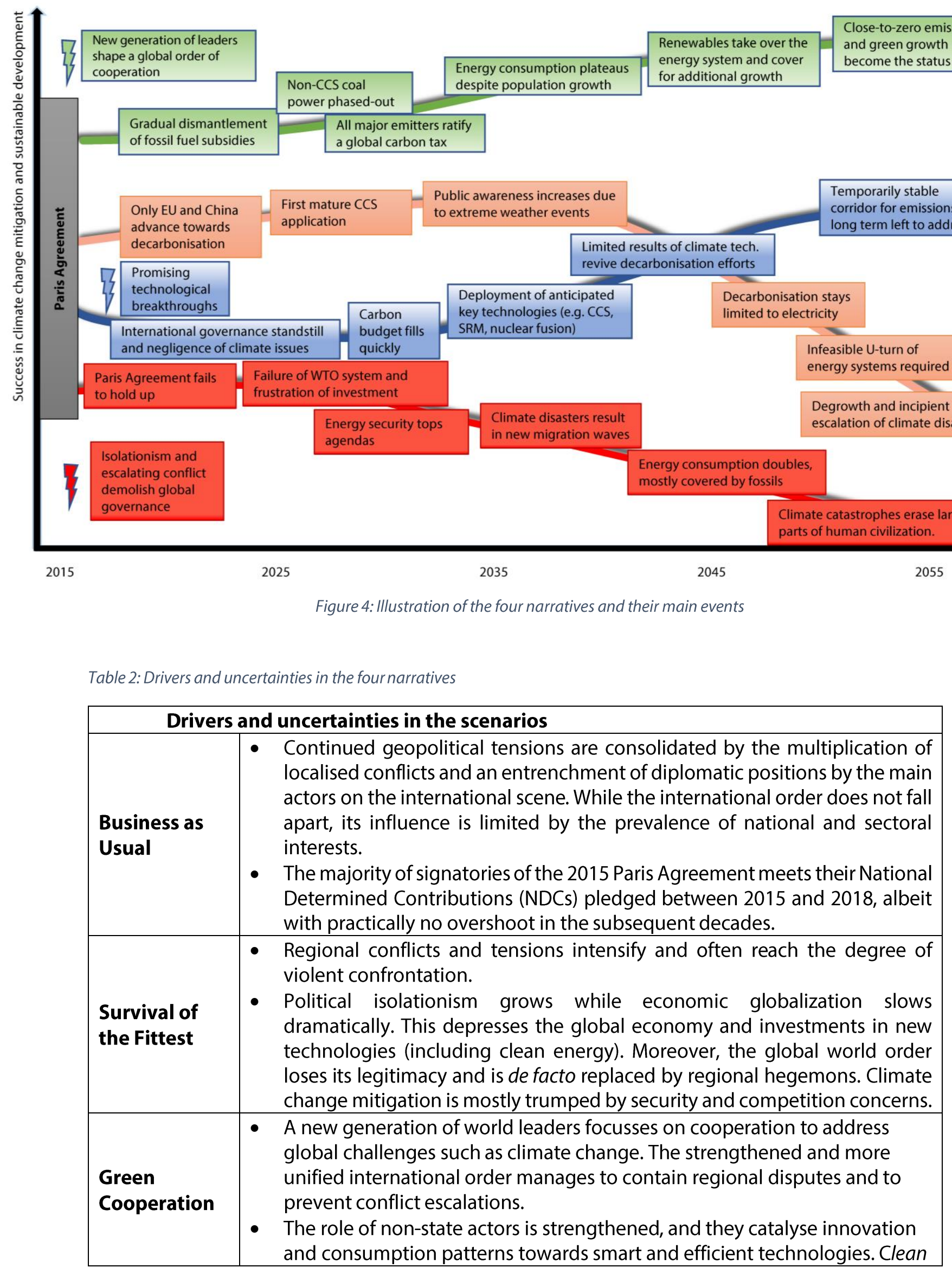




\begin{tabular}{|l|l|}
\hline & $\begin{array}{l}\text { modernity further shifts the public opinion towards strong climate change } \\
\text { policies. }\end{array}$ \\
\hline ClimateTech & $\begin{array}{l}\text { Technological advances in climate and energy engineering promise to offer } \\
\text { a multitude of solutions. While early indications of upcoming breakthroughs } \\
\text { already affect policy and public opinion, the global race for low-carbon } \\
\text { innovation also leads to challenges and path dependencies of its own. } \\
\text { - The status quo on the geopolitical scene is prolonged, whereby tensions } \\
\text { continue but do not lead to an all-out conflict. National concerns cool down } \\
\text { multilateral cooperation considerably until new threats bring all parties back } \\
\text { to the table. }\end{array}$ \\
\hline
\end{tabular}

\subsection{Business as Usual}

\subsubsection{The Paris promise: between targets and ambitions in the 20s}

In the Business as Usual scenario, geopolitical tensions and localised conflict that worsen human and economic conditions continue in the late 2010s and early 2020s, not only in the Middle East and Africa but also in OECD countries. While this geopolitical situation does not directly impact the accomplishment of climate targets set by countries in their NDCs, political priorities are diverted from climate and energy issues.

The 2015 Paris Agreement was only a first step and poses several additional challenges: While ambitions on mitigation objectives are converging, much still needs to be done with regards to actual measures. The climate targets that were announced in the NDCs following the Paris Agreement are mostly met in the Business as Usual scenario. However, the re-evaluation of those targets and associated measures, decided to take place every five years, brings only modest changes to the original ambitions of the signatory countries. Between 2018 and 2025, among the top $10 \mathrm{GHG}$ emitters that signed the Paris Agreement, only the EU and China, effectively scale up their efforts. Further questions relating to financing schemes to support developing countries' plans as well as frameworks that could foster technology transfers have yet to be addressed. Schemes such as the Green Climate Fund and the Global Environment Facility are present on paper but fail to kickstart effectively. This limited progress is connected to a general increase in struggles to find a global common stance: Many United-Nations initiatives (including the UNFCCC) hold firm but face a cooling of international relations, a growing divergence of national interests, and thus, a weakening of their legitimacy and influence.

Carbon pricing is not enforced globally but instead relies on regional, national, and local implementation. In the mid-2020s, the EU policies for a green transition become more stringent although political differences and national interests leave a decarbonised Europe still far from reality. The United States do not witness major changes with regards to clean energy. Country-wide carbon pricing stays absent, and the regional extents of decarbonisation efforts are heterogeneous. Some states rely on cap-and-trade initiatives, but others refuse to introduce new bills, often due to pressure from large upstream (fossil fuel) and downstream (conventional) energy companies, which stay crucial to many local economies.

Regional initiatives, being more modest than initially hoped for, do not spur the investment in R\&D and the deployment of renewable energy generation and energy efficiency that would be necessary to tackle the growth of energy demand in much of the developing world. As a result, the carbon intensity in emerging economies increases in the next decades. India's climate policy makes incipient progress through stricter vehicle standards and gas power plants. But emissions from coal-fired electricity generation rise steeply and make India one of the world's largest polluters. More generally, in the Global South, the diffusion of zero-emission micro-grid installations, targeted green investment programs, and a significant amount of new hydropower projects, whether through private actors or multilateral development banks do not suffice to curb carbon emissions in these 


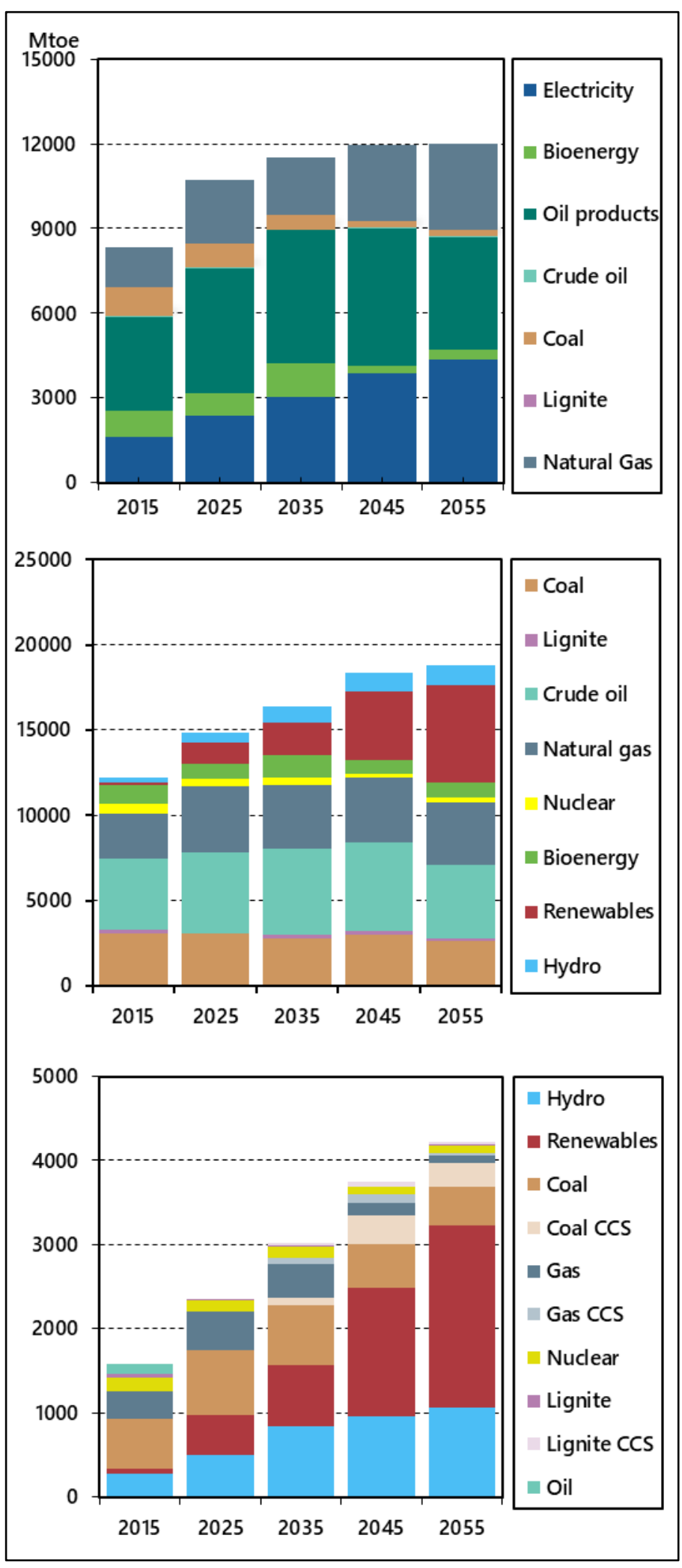

Figure 5: Global results for final energy consumption (top), primary energy production (middle), and electricity generation by source in Business as Usual regions. Distributional questions within the North-South divide remain unsolved, driving most of the Global South into prioritizing energy security rather than global sustainability.

This trend is partly offset by more climate-friendly developments among several large polluters. China consolidates its role as a green force within a polycentric Asia and, thereby, becomes a pillar for future international climate cooperation. However, despite large investments in renewable energy generation and a stagnating coal demand, fossil fuels remain an integral part of the Chinese energy system.

The MENA region takes a more pro-active stance towards decarbonisation with an increased number of initiatives towards clean energy, especially for net-importers of fuel. For exporters, these initiatives remain mostly symbolic, and an effective turn to deep economic and energy sector reforms is constrained by conflicting interests with the regional fossil fuel sector that becomes ever more dependent on domestic consumption.

Despite the absence of a global carbon pricing mechanism and the heterogeneous, largely insufficient schemes for supporting investments in renewable energies in the first decade of the scenario, some developments favour the future reduction of global GHG emissions. For example, while global demand does not yet switch away from coal in the 2020s, new solutions start to emerge at the turn of the 2030s, for instance in the form of first mature carbon capture and storage (CCS) applications and efficiency increases for renewable technologies.

Altogether, the 2020 s see renewable energy and fossil fuels co-exist (Figure 5). Transport, especially in the Global South, depends on fossil fuels, whereas the diffusion of electric vehicles accelerates slowly in many industrialised economies. Despite significant advances towards decarbonisation in China and Europe, disruptive changes of conventional energy systems are virtually absent. Fossils still dominate in the rest of the world, supported by the absence of joint political action or technological advances.

\subsubsection{Catching up after 2030?}

The pace of the global energy transition accelerates somewhat in the 2030s and 2040s as a consequence of stronger climate change effects 
and technological advances. The number and magnitude of extreme weather events such as draughts, wildfires, storms, and excessive precipitation grows, which also affect North America increasingly. This leads to a gradual change in the public perception and eventually redirects the U.S. federal leadership towards a stronger stance on climate policy. The fresh ambitions enable a new and significant multilateral push towards decarbonisation, in which all large emitting countries take part. This effort comprises coordinated action to decrease carbon leakage, stricter national climate policies, and financing schemes for supporting climate adaptation. However, the agreements continue to stay behind initial expectations in a world order that has never fully moved on from political tensions between major powers. They merely lead to a stagnation of fossil fuel consumption rather than a shift of the global energy system, among other reasons due to the continued absence of a global $\mathrm{CO}_{2}$ price.

Concerning technological advances, the transport sector is subject to important changes, with electric vehicles experiencing significant cost decreases by the late 2020s, although wide-scale deployment only takes place in the following decade. Traditional combustion-engine cars persist in many parts of the globe. Freight and air travel do not undergo any major changes. Renewable electricity generation becomes increasingly cheaper relative to electricity generation from coal and gas. CCS enters power generation on a larger scale, yet the technology stays expensive and its efficiency stays below expectations. Over time, renewables and, to a lesser degree, CCS dominate the global fuel mix and cover the steep increase in electricity demand from all sectors towards 2050. Other technologies, such as nuclear fusion, are far from being commercially available, although research in those technologies continues nevertheless.

A global substitution of fossils by renewables only takes place in power generation and in the 2040s. Examples for a deep decarbonisation of industry and transport are rare, which is why fossil fuels are still essential, partly due to the availability of the CCS technology. Nevertheless, efforts finally lead to a stagnation of fossil fuel production and consumption despite global population growth.

Global collective action for climate change mitigation still operates within a UNFCCC-type framework. However, the associated emission reduction is too low and comes too late: By then, not only a smooth transition but a U-turn of the energy system and disruptive shift to negative net emissions would be necessary to have a chance at keeping cumulative emissions in a $2^{\circ} \mathrm{C} \mathrm{limit}$.

The growing impact and quantity of extreme weather events crucially raises awareness of the public and decision-makers. However, fears of too harsh and expensive reactions by fossil fuel owners threatened by asset stranding - and a lack of common ground in dealing with distributional questions on a global scale lead to a reluctance in enacting a deep transition of the energy system and fuel-dependent economies. The late re-invigoration of mitigation efforts is too little and too late to prevent the intensification and surge in - still localised - climate change-induced catastrophes towards 2050 and beyond. As a result, multiple regions of the world are about to enter a period of de-growth, as adaptation costs escalate globally.

\subsection{Survival of the Fittest}

\subsubsection{A world apart}

In the Survival of the Fittest scenario, policy-making in Europe and North America becomes increasingly influenced by protectionist and nationalist interests. Hence, their relevance in the international economic governance system declines in the 2020s which makes any multilateral process much less likely to bring efficient results. Agreements on trade and economic cooperation are instead determined within regions, thus accelerating the transition to a polycentric world order dominated by regional powers.

Influenced by a rationale rooted in isolationism, the United States drastically reduce their efforts in the Middle East and Eastern Europe around 2020. Especially the reduced military presence in the Middle East leads to a disaggregation of alliances into competing local factions. These developments have a direct effect on the economic and political stability of oil exporters, including the Gulf States, 
which become ever more vulnerable to global economic conditions. Political struggles eventually lead to the disaggregation of the Gulf Cooperation Council, and a climate of tension and hostility characterises a gulf apart. This even leads to localised instances of military confrontation, and the conflict expands to the wider Middle East and North Africa. Fuelled by mounting tensions on domestic fronts, exporters fail to achieve a common stance on oil policy. Without the leadership of Saudi Arabia, OPEC continues to exist on paper, but it fails to establish a common output policy

Therefore, and despite conflict and insecurity, global oil and gas output is only subject to mild disruptions. Rather, each country engages in a self-preserving and short-term oriented approach, and missing coordination leads to a surge in production and a drop in oil prices.

At the same time, conflicts erupt elsewhere. Among them, in the South China Sea, isolated yet violent confrontations happen between China and a coalition of smaller countries backed by the United States. Although both powers avoid the escalation to an open conflict, the continued struggle severely damages the relations between China and the US, reducing their diplomatic ties to a minimum.

Conflicts in the South Caucasus also put a strain on European solidarity. The continent is divided between "hawks and doves" over how to best deal with Russia. Weakened transatlantic relations leave Europe and the U.S. alienated, and European decision-makers are torn when it comes to redefining alliances. Between rechtsruck and realpolitik, a fragmented Europe has only little basis to form common foreign or fiscal policy. This limits economic progress and the possibility to mediate in international conflicts. Global tensions also heighten concerns over Europe's access to affordable and secure energy, moving decarbonisation out of the focus in the 2020s. Based on the principle of the lowest common denominator, a fragmented Europe continues to cooperate on advancing the energy transition although at slower pace and with weaker ambitious.

\subsubsection{International climate policy at a standstill}

The Paris Agreement fails to hold, as (supply) security trumps climate policy on the national agendas of fuel-importing countries, while multilateral diplomacy quickly erodes due to a general sense of mistrust. This leads to a global institutional order where the UNFCCC loses its legitimacy. In parallel with Australia, the Latin Americas, Russia, South Africa, and multiple Southeast Asian suppliers, the U.S. ramp up coal production, consolidating the fuel as the pillar of many countries' energy systems. An even larger surge takes place in the natural gas sector, whose importance increases to meet the steep increase in modern industry and residential energy needs in the absence of a global transition to electricity.

Green transformation efforts become increasingly dependent on informal alliances and bilateral relations. China, in an ever-closer cooperation with the EU, continues to gain importance in this regard, consolidating agreements on technology transfers, green investments, and development programs, not only with European countries but also with parts of the developing world. Chinese infrastructure investments are on the rise in Africa and Asia alike. The objectives behind these moves are diverse but mostly directed towards filling the vacuum left by the weak international system, thereby consolidating the role of China as the (supra-) regional hegemon.

Global economic growth slows down from the early 2020s onwards, in large part due to the failure of the WTO system and the re-enforcement of trade barriers and protectionist policies. The proautarkical regulations and a lack of support for coordinated projects lead to a frustration of private investment, which drifts away from technological innovations in the fields of energy generation, efficiency, storage, and CCS as well as the transport sector. Thus, in the 2030s, the rate of technological progress slows down, deployment of new technologies lacks support, and the private sector altogether fails to propose adequate solutions for mitigating climate change.

Instead, increased global competition in fossil fuel extraction and the widespread deployment of coal and gas power plants lead to efficiency gains in conventional fuels and technologies. Energy consumption increases continuously and almost doubles until 2045 (Figure 6). The composition of 
demand follows "traditional", i.e. fossil-intensive, growth patterns without much technology switch. The (moderate) increase in global electricity generation sees also a somewhat growing role for renewables, but the large majority is met by conventional power plants.

While concerns over national security hamper international climate negotiations, energy security and air and water quality also rank high on the agendas of many countries. For some large net-importing economies, most notably Europe and China, public health issues start to play a major role in energy policy considerations in the 2030s. This leads to a re-orientation of their focus on domestic resources, with a strong emphasis on solar and wind power, while at the same time ensuring higher end-use efficiency. North America also continues to rely strongly on its domestic unconventional oil and gas reserves, further driving up global fossil fuel demand. However, this trend is partially offset by a number of cities and state-level actors which push for a green transformation. This Quixotic approach creates an atmosphere of clean enclaves, which further cements heterogeneity and divergence within the continent.

Without strong international organisations to coordinate policies tackling energy consumption or end-use efficiency, the $2{ }^{\circ} \mathrm{C}$ carbon budget is filled early in the 2030s. Therefore, in the following decades, climate change-related catastrophes become frequent. The persistent absence of international cooperation between states and the diversion of public spending away from potential mitigation or adaptation measures further hinder financial and technological transfers to the countries most affected. The developments fail to create a necessary global common sense of solidarity, since estranged governments oppose free-rider gains and focus on local adaptation measures.

As a result, climate change becomes an influential factor for international migration in the late 2030s and leads to a multiplication of security threats. Not unlike the refugee crisis in the mid-2010s in Europe, albeit at a larger scale, a new wave of mass migration overwhelms international assistance and further fuels state-on-state as well as domestic conflicts. This new migratory crisis and the resulting tensions furthermore hinder government responsiveness in many host countries, thereby delaying even further any

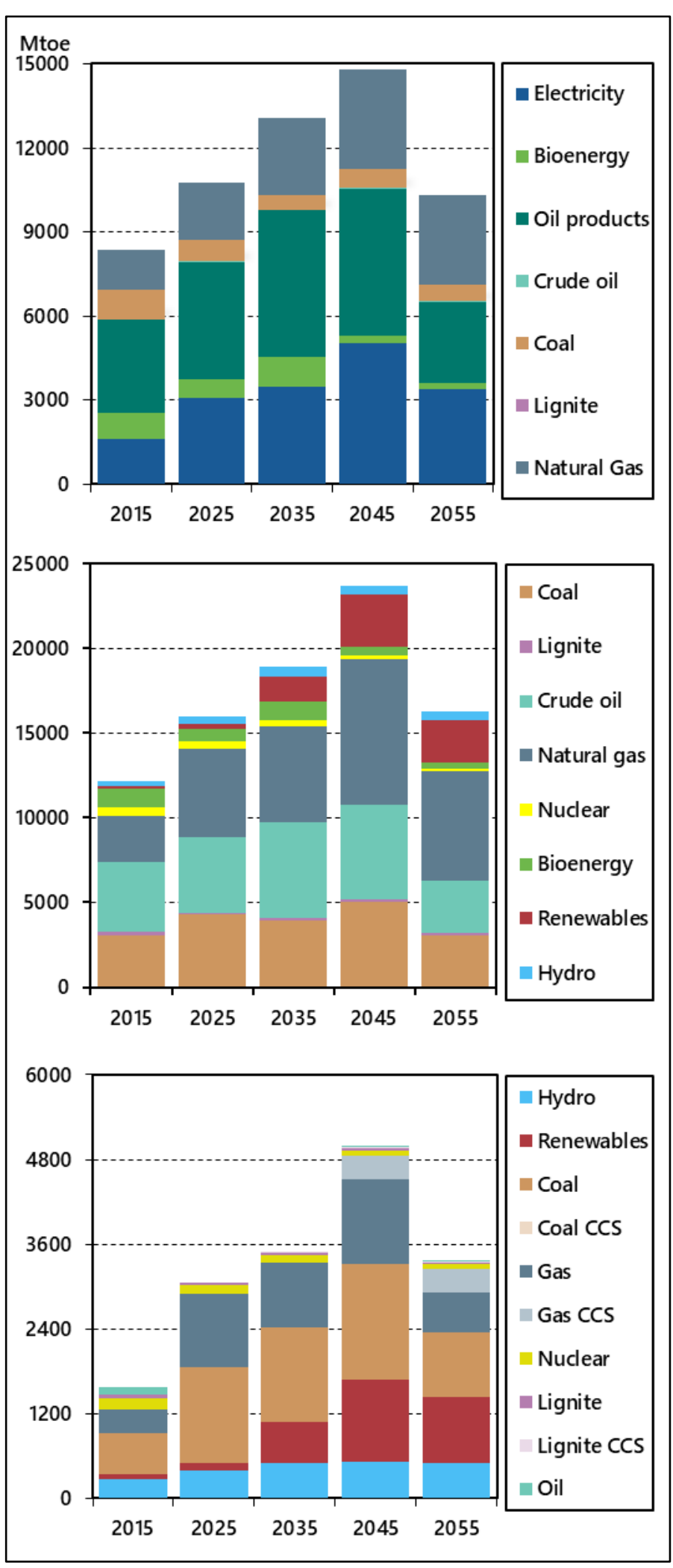

Figure 6: Global results for final energy consumption (top), primary energy production (middle), and electricity generation by source in Survival of the Fittest 
concerted climate change measures, increasing adaptation costs drastically.

In the endgame, towards 2050, global warming gets out of control and results in global large-scale natural catastrophes. Whereas the richest nations are forced to afford the exploding costs of adapting to this world and pay major shares of their GDPs to survive, vulnerable regions that cannot afford these measures become uninhabitable, and productive factors are largely destroyed. Accompanied by regional wars over remaining resources, the world will see veritable global degrowth, de-industrialisation, and, therefore, a slump in energy production and consumption. Clearly, Survival of the Fittest sees the world as we know it cease to exist.

\subsection{Green Cooperation}

\subsubsection{Clean Peace}

In the early years of the Green Cooperation scenario, decades of conflict in the Global South push northwards, transported by migration and market turbulences. Societies in the Global North are increasingly tense and see the quick rise of nationalist and reactionary forces, which begin to gain the upper hand throughout Europe and North America. However, this eventually causes a strong push-back by a revived liberal civil society, which elects a new generation of progressive leaders into office. Aiming to rebuild their societies and end conflicts, this young class of leaders values the potential losses from non-cooperation in an interdependent world higher than the prospective gains through confrontation.

Therefore, this scenario sees a quick return to peace where conflicts soon de-escalate in key geopolitical regions such as the Middle East, South Caucasus and the South China Sea. The international order is characterised by a strong stance against sedition and discord, which moves rather fiery regional players to leave conflicts aside. Some internal power disputes remain, e.g. in the Greater Middle East, but the frequency and scope of armed conflict diminish and do not resurge throughout the 2050s, much due to a continued common policy of conciliation among the world's major powers.

The effects on international relations and on fossil fuel prices are mixed. On the one hand, the phaseout of armed conflicts in the Middle East is accompanied by a renewed dialogue between the major players in OPEC. As relations between Saudi Arabia and Iran normalise, oil producing countries are finally able to reach an effective and long-lasting agreement on withholding production. This has nevertheless only limited influence on oil and gas prices because consumption in many netimporting countries decreases due to technological advances and a shift to alternative energy sources from the 2020s onwards. While North America becomes increasingly energy self-sufficient, Europe, India, and China benefit from the détente, which allows them to consolidate their security of supply, for example through a diversification of gas imports. Growing fossil fuel demand in SubSaharan Africa is the main counterbalancing force against this trend in the first decade of the outlook period, driven by fast economic growth as well as rising demand for transport fuels.

With security and economic concerns diminishing, internationally coordinated efforts towards climate change mitigation gain momentum. The 2015 Paris Agreement is upheld, and the emission reduction targets are tightened in the 2020s. The first half of the 2020s furthermore sees a paradigm shift, so that decarbonisation and poverty alleviation are increasingly considered as dual objectives. In addition, national economies become increasingly interconnected, thus allowing for better integrated energy systems and overall greater international cooperation on mitigation measures. This new dynamic contributes throughout the 2020s to the fast dismantlement of fossil fuel subsidy programmes as well as to a linkage and expansion of emission trading schemes, thus allowing for an increase in climate policy ambition and a reduced cost of emission mitigation in the following decades.

As a result, decarbonisation policies support innovation and sharp decreases in costs for renewables, and their fast deployment leads to a successive phase-out of fossil fuels (Figure 7). In the 2030s, the global electricity mix is free of coal and dominated by renewables, which have been in the focus of 


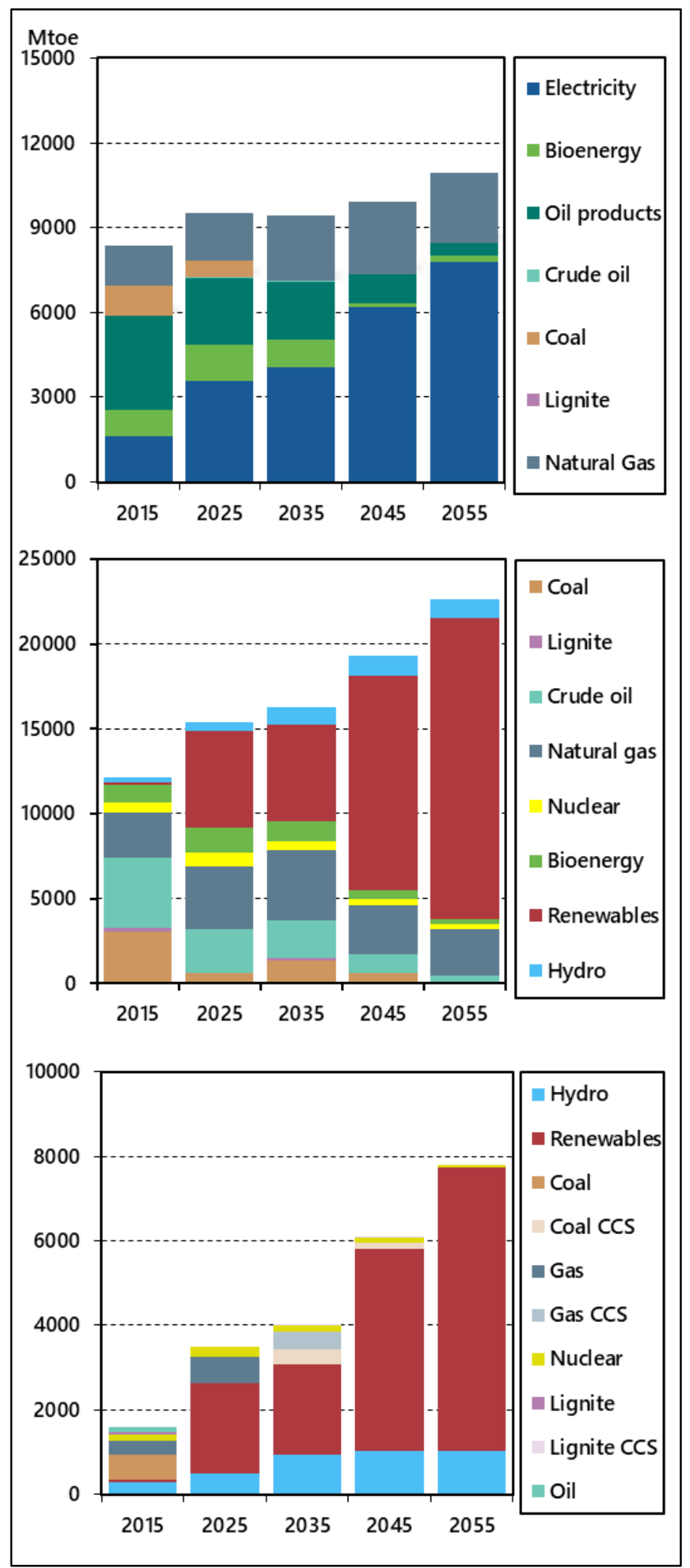

Figure 7: Global results for final energy consumption (top), primary energy production (middle), and electricity generation by source in Green Cooperation public and private investment as opposed to CCS technology. However, CCS only plays a temporary role by extending the phase-out of fossil fuels into the 2040s. The use of oil products is substantially decreased as well, in particular due to strong policies that push towards an early transition of the transit sector throughout.

\subsubsection{A future of green synergies}

While the role of central governments remains crucial for the global energy transition of the next decades, more and more solutions are being put forward through other channels, involving not only the private sector, but also transnational bodies, cities, and consumers. The global transition therefore lives from synergies that are reached by combining top-down approaches, mostly in the form of strict carbon taxation and green subsidies, and bottom-up action from all actors.

For transitioning economies, the scenario foresees an increased role of multilateral development banks and micro-finance programs. Ensuring near-universal energy access under clean standards becomes a focus of these initiatives for much of rural Africa and South-East Asia where, in spite of a reduction of conflicts, state capacity remains limited. Distributed generation and decentralised renewable energy solutions leapfrog the slow-moving deployment of centralised power and rapidly accelerate energy access. As a result, infrastructure, private sector investment, and productivity improve quickly from the mid-2020s onwards in the Global South. Generally, there is less need for energy infrastructure (expansions) in this scenario due to the substantial success of energy efficiency efforts in all energy consumption sectors compared to the Business as Usual scenario. Therefore, and despite rapid population growth, final energy consumption first plateaus in the 2030s. Subsequent increases are of only modest nature and covered almost entirely by growth in clean electricity, which largely dominates the global energy mix in the 2040s.

Prosumers gain importance and consolidate the image of responsible citizens, thanks to matured decentralised system designs, the availability of microfinance in developing countries, and policy support schemes as well as harmonised legal frameworks. Hence, in the 2020s and 2030s, prosumers become a key driver of the Asian 
energy transition and contribute to switch away from dirty electricity sources in other fossil-fuel dependent regions.

Finally, the interconnectedness of economies and the political support for a global energy transition lead to an acceleration of the integration of national energy agendas with one another. Early progress towards a global carbon tax is made in the early 2020s and initially only ratified by a handful of nations. However, the group widens quickly and includes all major emitters in the 2030 s.

The scenario period witnesses an intense urbanisation process, both in the Global South and in OECD countries. However, energy efficiency efforts are sizeable and much of the energy demand in the urban buildings and transport sectors is met by clean solutions, thus avoiding a lock-in of carbon intensive infrastructure in developing regions. In many growing cities, urban density allows for integrating district heating and cooling networks fuelled by low-carbon energy sources or waste heat from industrial plants. New building materials, which are the result of the large support of R\&D, allow for the construction of new megacities without a large carbon footprint.

As low-carbon urban mobility becomes a top-priority, electric vehicles take over the streets in the 2020 s, but large investments in new and innovative modes of mass public transit prove the only way to manage the quick growth of cities sustainably. Major cities therefore push towards bans or strong restrictions on private car traffic, which are welcomed by their inhabitants.

This is part of an overall shift in individual behaviour which results from a symbiosis of policy, culture, and technology. Progressive cities welcome the international climate efforts and vie in the creation of green urban ecosystems whose leitmotif is the urban oasis: a modern and efficient yet green utopia. The rapid improvement in living conditions, especially in areas that observed high rates of air pollution, seizes citizens and improves the public awareness for environmental issues drastically. With the change of generations, a close-to-zero-emission environment becomes the status quo. Increased specialisation, lower risk, and large public programs lead to a culture of investment and research, which allows progress in numerous key technologies that enable an affordable transition to this clean modern vision, such as 3D and 4D printing, novel materials, and quantum computing.

Thanks to early, widespread, and deep emission mitigation, climate change only has localised impacts in the medium-run, to which the international community reacts promptly with financial and technological transfers and adaptation measures. By 2050, all these factors combined will have led to the achievement of an inclusive renewable energy transition, which prevents extensive global warming. In combination with further advances in negative emission technologies beyond 2050, green growth has become reality.

\subsection{ClimateTech}

\subsubsection{Time is on my side}

Similarly to the Business as Usual scenario, diplomatic relations between the large regional powers remain steady over the outlook period of this scenario. Geopolitical tensions and localised conflict in the late 2010s and 2020s worsen human and economic conditions across the globe. The international governance system comes to a standstill at the turn of the 2020s at the expense of climate and energy issues, in part due to the failure of any major actor to take the lead in multilateral, rules-based (international) institutions.

However, and at the same time, research in climate intervention shows promising results, so that technologies such as carbon capture and storage (CCS) and solar radiation management see their performances increasing while costs are cut down. Although these technologies are still at an early stage of development in the 2020s, their perceived benefits alone affect climate policy in the following years significantly. News of the forthcoming technical revolution generate an atmosphere of public euphoria that is fortified with the widespread perception that climate questions are already solved. 
Although not seconded by scientists, politicians rejoice in the diminished pressure to decarbonise their respective economies and divert political effort to other topics such as economic growth. Therefore, the global economy remains strong over the entire outlook period, accompanied by significant worldwide population growth in Africa and South-East Asia. However, economic development remains unequal, due to an international order that continues to be tense and does not provide a vital setting for balanced free trade and technology transfer. Despite the loss of focus on climate policy, environmental policy becomes important as public health is another topic rejuvenated by a public that expects a transition to a clean lifestyle.

The loss of momentum in decarbonisation policymaking combined with the frustration of diplomatic relations between the large global powers affects international climate negotiations. While the Paris Agreement leads to a deceleration of fossil fuel consumption growth until 2035, progress soon slows down, as the initially formulated NDCs are not followed by more ambitious pledges. This failure in emissions reduction is also due to rapidly rising energy demand driven by population growth and urbanisation. Some isolated attempts at climate change mitigation in the first half of the outlook are, however, noteworthy: Europe scales up its ambitions, and China exploits the tech dawn to finally move beyond the production of cheap tradeables. On this course, China redefines its comparative advantage and is determined to take the global lead as an R\&D powerhouse.

A Business-as-Usual world with the (absent) climate policy of Survival of the Fittest and technological ambitions beyond Green Cooperation erects an energy system that exhibits a steep growth of demand, quick technological change, and uneven developments (Figure 8). Throughout the first half of the outlook, strong gains in fossil fuel demand nearly double final energy consumption, and a medium-paced growth of the electricity sector comes with new renewables and conventional plants alike. As a result, GHG emissions increase dramatically and exceed the Business as Usual case by far. With internationally concerted efforts to tackle $\mathrm{CO}_{2}$ emissions facing a dead end, the $2{ }^{\circ} \mathrm{C}$ carbon budget is nearly filled by the early 2030s, thus inducing more frequent extreme weather events.

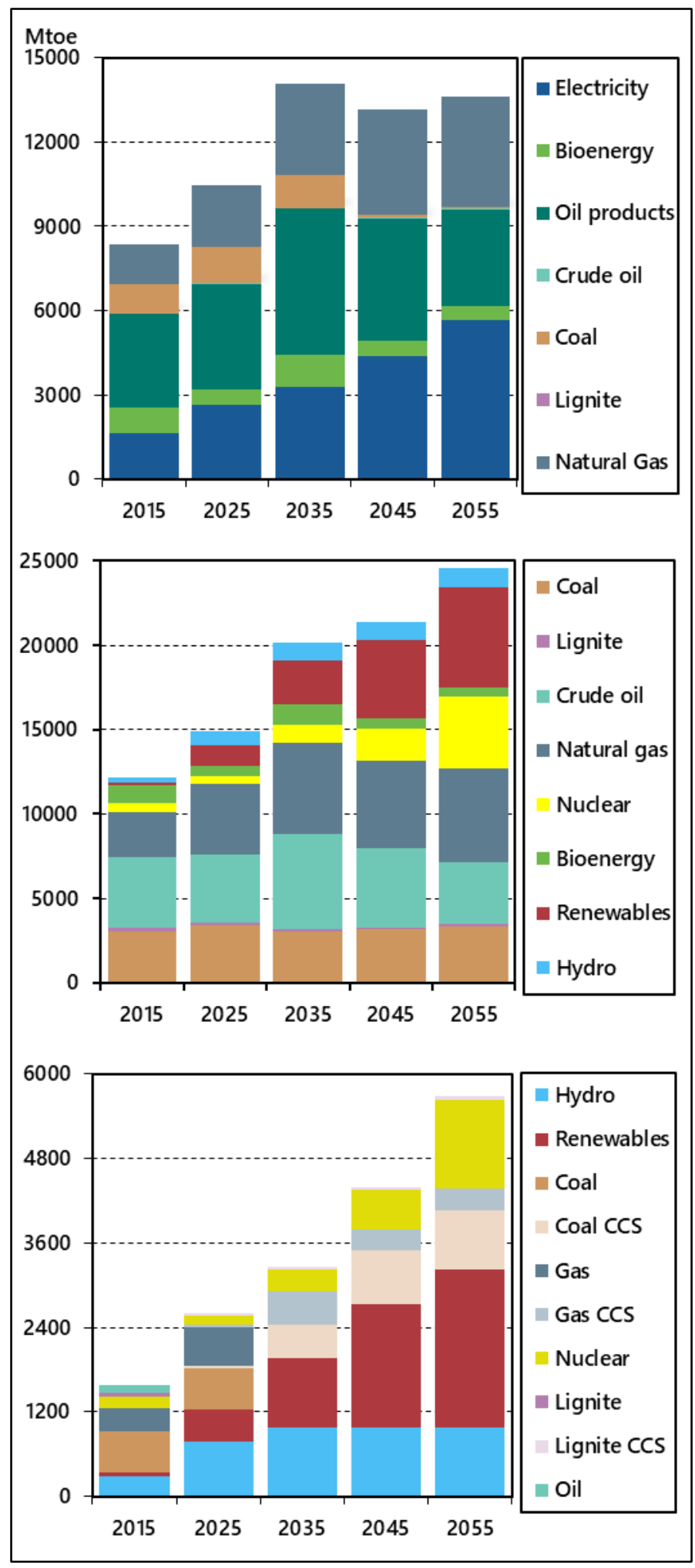

Figure 8: Global results for final energy consumption (top), primary energy production (middle), and electricity generation by source in ClimateTech 


\subsubsection{A tale of sulphates and nucléocrates}

Final breakthroughs in key technologies of climate and energy engineering in addition to various forms of geo-engineering are seen in the 2030s. However, the adolescent technologies still teeter into the wider energy system on their quest for an ultimate role.

First, direct air capture witnesses strong cost cuts due to the development of modular units that enable a quick deployment. Although, initially, the efficiency and applicability of the technology is still limited, direct air capture soon becomes the symbol of omnipresent action to tackle emissions, as the (now smaller) devices are installed virtually everywhere. Air capture is furthermore favoured by decision-makers for its ability to not only capture emission flows but also stocks.

A second key technology, solar radiation management (SRM) receives a peak of attention during the 2030s. In the public eye, the technology is celebrated as the liberator of mankind from climate change due to its potential to have a large and lasting effect on emissions. Nevertheless, after a multitude of tests during the first years of its availability, scientists begin to warn that SRM, and more specifically aerosol sulphate, may deplete the ozone and bring significant changes to the hydrological cycle. While the warnings are initially unheard by politicians, effects become discernible and measurable, affecting nearly all kind of maritime value creation. Also, certain SRM techniques threaten to be developed into weapons, thereby violating the 1976 Environmental Modification Convention. As a result, the unilateral use of SRM is eventually prohibited and only scaled up slowly within multilaterally concerted initiatives.

To control the risks associated with the novel technologies, new institutional frameworks for international cooperation emerge. Novel multilateral funding sources, such as development banks for supporting improvements in climate engineering, are created within the UN framework, whose political influence decreased significantly over the previous decades. At the same time, a new intergovernmental body, inspired by the International Atomic Energy Agency, is founded with the purpose of promoting the safe use of climate engineering and providing international safeguards against their misuse.

As climate engineering affects emissions but stays ultimately behind its enormous initial expectations, the reopened discussion about climate change mitigation sheds light on the elephant in the room: Energy consumption has risen at a pace that the still-incipient climate technologies fail to compensate. However, extremer weather events and the widespread coverage of the rise and fall of hopes for adaptation-based solutions have created a broad awareness for climate change. Therefore, the re-empowered international community manages to commit to a global $\mathrm{CO}_{2} \mathrm{cap}$. However, numerous exemptions are given and remain a common practice because of fears for national industries and the presence of emission reduction technologies. Nevertheless, the energy system in the 2040s (Figure 8) experiences a reduction of fossil-fuel consumption and sees the death blow to direct coal usage, but natural gas and crude oil remain crucial in the final energy mix. Priority is given to completing the decarbonisation of electricity.

One of the technologies that sees sudden advances is nuclear fusion. Although, particularly during the 2030s, the technology's value is questioned due to high costs, its promise to break the energy trilemma by providing affordable, secure, and clean energy in the long run is a tempting vision. Especially China, which is responsible for much of the research during the 2020s that finally leads to a breakthrough, is set to supply the majority of its exponentially growing electricity demand with nuclear fusion. The decision to go all-in on this technology is, in early times, mostly aimed at turning it into the greatest Chinese export. Its mesmerising effect on politicians creates a new generation of nuclear advocates who seek to pressure the "new saviour" of energy and climate into global power grids at all cost. However, the 2030s see virtually no application of the technology outside of China. Finally, towards 2050, more mature reactors are installed in other energy systems, despite continued controversies regarding their actual potential. However, outside of China, whose nuclear elite refuses to question the technology, applications remain limited. 
Elsewhere, cost cuts and novel technologies turn renewables into the major source of electricity with a global share of roughly $50 \%$. The other half of electricity demand is met by nuclear energy and highly-efficient CCS coal and natural gas power plants, which profit from strong R\&D investments even after their mature emergence around 2030. As a result, over all five decades of the outlook, there are only minor changes in global fossil fuel production except for a surge in the production of natural gas.

Altogether, the numerous breakthroughs - both fortune and a consequence of large investments buy time and lessen the burden of the energy transition, but eventually both decarbonisation and adaptation measures are necessary. The resulting system succeeds to curtail emissions and to prevent large scale climate catastrophes. Nevertheless, the negative emission technologies fail to provide a robust counterweight to the lagging decarbonisation and missing behaviour shifts. Hence, the emission trajectory is inherently fragile with respect to population and economic growth beyond the outlook period. This world can only be sustainable if technological progress continues to outrun growth. 


\section{Discussion and Conclusions}

\subsection{Comparing the four narratives}

The comparative assessment of emissions, energy service consumption, and electricity generation (Figure 9) shows discrepancies but also similarities between the four scenarios.

The four trajectories of final energy consumption show a strong divergence, with only modest increases in Green Cooperation, a stagnation of demand in Business as Usual that starts in 2025, and strong increases in ClimateTech and Survival of the Fittest. These two scenarios outgrow Business as Usual in terms of consumption by twofold in 2035 and 2045, respectively. Demand in ClimateTech is then disrupted by the shift towards stricter climate policies. In contrast, growth in Survival of the Fittest is only brought to an end by a global collapse.

Albeit with some variation, a more homogenous development occurs for the electricity sector. All scenarios witness a large increase of power demand that exceeds $150 \%$ by 2035 and reaches even a fourfold increase in Green Cooperation, where a first wave of electrification happens in the 2020s but only smaller gains thereafter. At this point, all four scenarios lie in a similar range. Then, however, the gap between the scenarios widens. In Green Cooperation, the green transition moves beyond energy and merges with a holistic change of technology and society into a smart world. Survival of Fittest sees the second-largest increase in power demand ${ }^{10}$ (before its eventual collapse) which, however, is the outcome of missing energy efficiency measures and unlimited growth. Business as Usual and ClimateTech provide a somewhat lower electricity growth at first, although slow system decarbonisation and new technologies lead to higher growth rates towards the end of the outlook for the latter.

$\mathrm{CO}_{2}$ emission trajectories reveal deeper insights. The quick global shift towards (green) cooperation in the corresponding narrative results in a U-turn of $\mathrm{CO}_{2}$ emissions, which have their most notable drop during the 2020s. Despite later increases in energy demand, emissions fall continuously and eventually converge towards approximately $20 \%$ of today's levels. On the other end of the scenario spectrum, the rampant growth of (non-clean) consumption leads to emission peaks that outsize current emissions by more than $60 \%$ in Survival of the Fittest. In this scenario, isolationism and the meltdown of the global order work as catalysts for climate change that accelerate the path towards climate catastrophes of unparalleled extent.

Final energy consumption growth

(percentage increase from 2015)

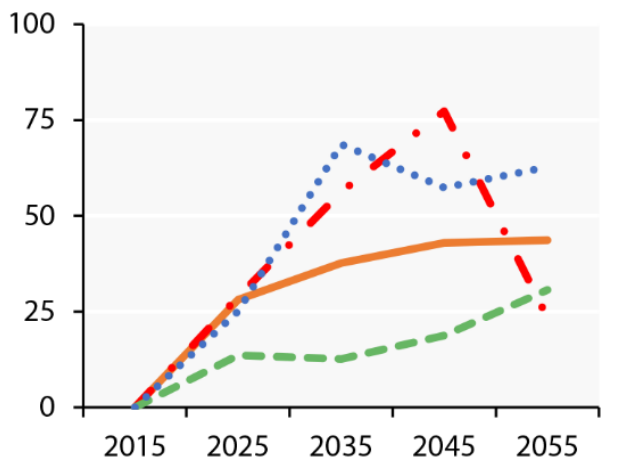

Electricity consumption growth (percentage increase from 2015)

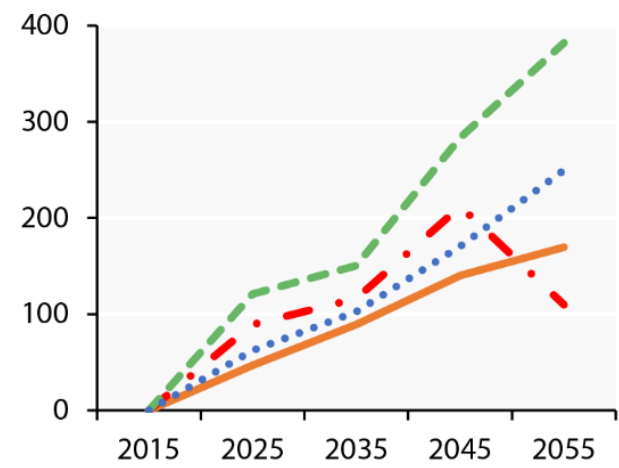

Net $\mathrm{CO}_{2}$ emissions (percentage change from 2015)

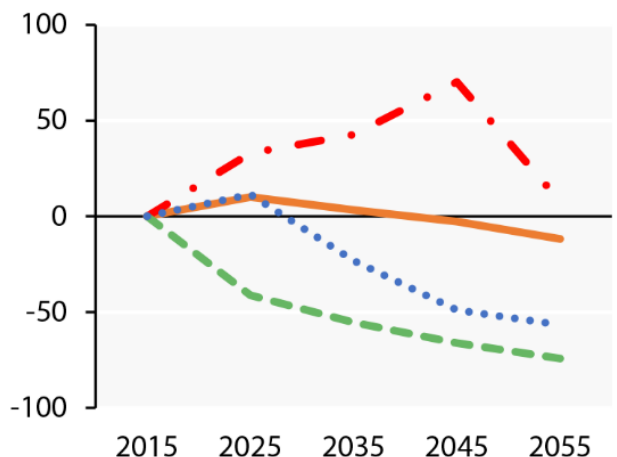

Business as Usual _ - - Survival of the Fittest _- Green Cooperation

...... ClimateTech

Figure 9: $\mathrm{CO}_{2}$ net emissions (left), final energy consumption (middle), and electricity consumption (right) as percentage change from 2015 values compared between the scenarios

\footnotetext{
${ }^{10}$ This suggests that the electrification of the economy - sometimes understood as an indicator how well energy transition and climate change mitigation succeed - may be misleading in this regard.
} 
Fossil fuel production

(percentage change from 2015)

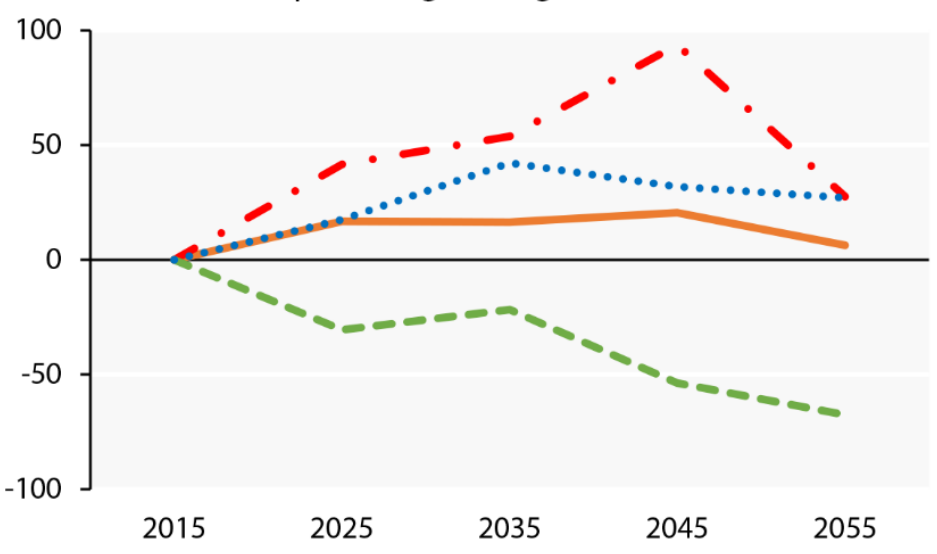

Renewable electricity production (percentage of total electricity generation)

Business as Usual $\quad-$ - Survival of the Fittest

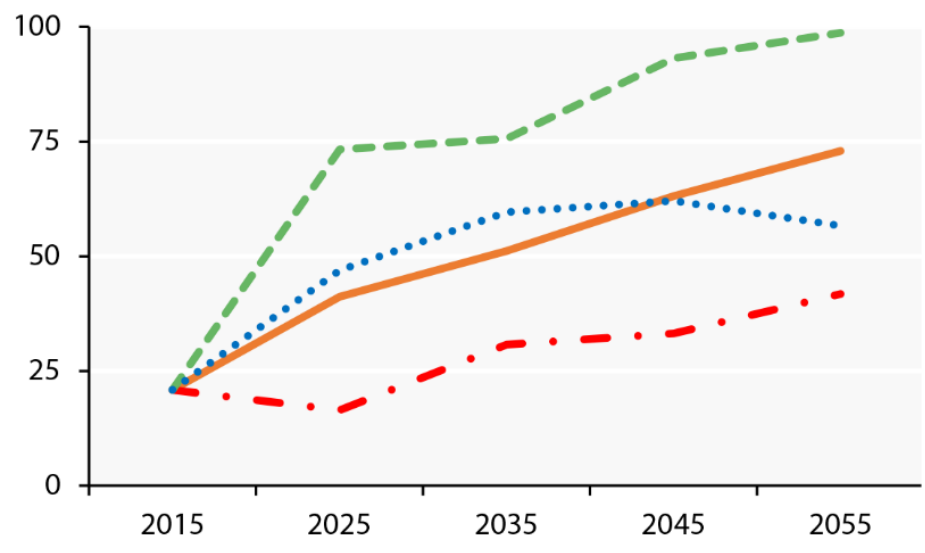

2015

...... ClimateTech

Figure 10: Fossil fuel production (left, as percent of 2015 values) and renewable electricity generation (right, as percent of total electricity) compared between the scenarios

For Business as Usual and ClimateTech, (net) $\mathrm{CO}_{2}$ emission trajectories are less self-explaining. Stagnating energy demand and meagre, apathetic decarbonisation efforts prevent a further escalation of emissions but fail to yield substantial reductions. ${ }^{11}$ Despite the surge in consumption, emissions in ClimateTech only rise modestly until the 2020s and see sharp cuts afterwards. This is first a result of the large-scale deployment of negative emission technologies, but second also an outcome of the powerful advances towards low-carbon electricity generation in later years. Although the scenario fails to decarbonise final consumption, the enhanced technology portfolio, a result of both fortune and investment, succeeds in achieving an almost $\mathrm{CO}_{2}$-free power sector until 2035. This is very much opposed to Business as Usual and Survival of the Fittest, which undergo some decarbonisation effort in the power sector but fail to achieve even this goal. Nevertheless, cumulative emissions in ClimateTech are far from the very low levels of Green Cooperation, and an emission path that stagnates at $50 \%$ of today's values may still fail to address the long-term climate needs adequately, especially with a view to population growth.

Renewables take over massive shares of the electricity mix in all scenarios (Figure 10). While Green Cooperation develops towards fully-renewable power generation by 2055, Survival of the Fittest sees the smallest share of renewable energy (but still reaches almost 50\%). ${ }^{12}$ Therefore, and similar to the conclusions about energy consumption, the share of renewables can be a misleading indicator to evaluate whether the world is on a successful path to climate change mitigation. Business as Usual and ClimateTech develop similarly, but low-carbon CCS plants and nuclear fusion technology in ClimateTech let Business as Usual fall behind ultimately.

The development of fossil fuel extraction (Figure 10) gives a diverse picture of modest-to-substantial increases over time, while only Green Cooperation exhibits major cuts. However, even in this case, fossil fuels are only cut back to approximately $30 \%$ of the current production, as natural gas fuels the hardest-to-electrify industries, and also a small share of oil production remains. In contrast, in Survival of the Fittest, there will be a surge in the production of fossil fuels that reaches almost double the current production levels in the 2040s. ClimateTech produces more fossil fuels than Business as

\footnotetext{
${ }^{11}$ Hence, to some extent, Business as Usual can be understood as a postponed Survival of the Fittest, where energy production patterns and cumulative emissions are on a pathway to exceed the $2^{\circ} \mathrm{C}$ target towards the end of the outlook and a sustainable solution remains out of sight.

12 The share of renewables is the only trajectory in Survival of the Fittest that seems unaffected by the global collapse; this is because the fittest, who survive in the eponymous scenario, eventually include nations such as Europe and China, who invest large amounts in renewable technology long before the 2050s.
} 
Usual due to the strong reliance on CCS and negative emission technologies that allow for a higher fossil fuel reliance.

\subsection{Lessons learnt}

Besides the definition of four narratives, our study provides an understanding of the interactions and interdependencies between policy, society, energy, climate, and technology. Some main lessons learnt include that the dangers from a rise of isolationism are twofold: Effective climate policies require global cooperation, and decarbonisation efforts will depend on encouraging investments in critical technologies. Therefore, a polycentric world without multilateral support for mitigation will be unlikely to prevent climate change. Also, the integration of economic and energy-related objectives and incentives (such as poverty alleviation, infrastructure modernisation, and private investment) is crucial, as the continued growth (not only in the Global South) is the proverbial "elephant in the room" (i.e. a mega-trend in foresight terminology). In this regard, our best-case narrative suggests that multinational cooperation, pushing both public and private investment into the right direction, and a holistic (societal) transformation can turn growth green. Also, the narratives underline the relevance of public opinion and societal transitions: Extreme climate events are most likely to raise awareness for climate issues and sway the public opinion towards decarbonisation. However, unless being universal, this bottom-up trend can still be outweighed by conflicting interests on other levels of society. In the best-case, however, society is eventually living green modernity - something that decision-makers can influence - following a holistic and integral societal transformation. While the complexity of drivers of climate policy and emissions may seem discouraging, the variety of tuning parameters for policy-makers should be viewed as an advantage.

Furthermore, the analysis provides guidance on the monitoring of climate change mitigation. Especially our worst-case narrative proves that two prominent benchmarks - the share of renewables and electrification of the economy - may be misleading pointers. Instead of that, we propose a set of unique indicators to track which narratives may realise (listed in Appendix A).

Our holistic approach demonstrates how the advantages of a qualitative approach in including the complex interactions and non-linear dynamics of global policy, society, and energy can be combined with the consistency and precision of a quantitative model. However, while advocating for a better representation of geopolitical and societal factors in energy systems modelling and scenarios, we realise that our study may come short of its ambitions. The level of heterogeneity of the expert group, the assessment of unknown unknowns, and the appropriateness of the time horizon may be debated and potentially enahnced, just as the translation mechanism into numerical parameters leaves room for future improvement. More direct approaches to incorporate social and political variables in (energy) models will be necessary to improve robustness. On this path, our analysis should be only understood as an initial step rather than the final goal. 


\section{Appendix A. Indicators}

Indicators (Table 3) can identify which one of different scenarios eventually develops. They can "measure change toward an undesirable condition", "evaluate change over time", and have "diagnostic power" [27, p. 135]. Indicators are unique and detectable manifestations for each narrative and can thereby serve as transparent early-warning signals for observers.

Table 3: Indicators for all four scenarios

\begin{tabular}{|c|c|}
\hline \multicolumn{2}{|c|}{ Indicators } \\
\hline $\begin{array}{l}\text { Business as } \\
\text { Usual }\end{array}$ & $\begin{array}{l}\text { - Geopolitical conflicts continue with no major escalation nor de-escalation, } \\
\text { and the global order persists but loses factual influence as national and } \\
\text { regional interests gain importance. } \\
\text { The global economy hardly grows because of modestly increasing trade } \\
\text { barriers and missing leadership. This adds to ambiguous policy signals } \\
\text { (especially regarding climate policy) and makes investments in energy less } \\
\text { focussed on certain tracks or technologies. } \\
\text { - Paris Agreement NDCs are respected but not followed by more ambitious } \\
\text { emission reduction (pledges) until the 2030s. Despite isolated the adoption } \\
\text { of carbon caps on national/regional level, there is no global carbon price. } \\
\text { Climate objectives rise in importance but continue to compete with } \\
\text { conflicting national and sectoral interests. } \\
\text { There is no universal societal shift towards or against climate change efforts, } \\
\text { although an increasing number of extreme weather events leads to a } \\
\text { gradual swing in perception. } \\
\text { The reduction of final energy consumption and the switch of its } \\
\text { composition proceed only slowly. Electricity generation is increasingly } \\
\text { decarbonised, but (non-CCS) fossils remain a significant part of the global } \\
\text { power mix. } \\
\text { Industrial processes slowly decrease their reliance on coal, but there is no } \\
\text { universal shift towards electricity (or even natural gas). } \\
\text { Technological change in transport is mostly localised and struggles to } \\
\text { combat the growth of private transportation with combustion-engine } \\
\text { vehicles as a result of population growth. } \\
\text { Decision-making is characterised by ambiguity, conflicting interests, and } \\
\text { shifting perspectives and influences. }\end{array}$ \\
\hline $\begin{array}{l}\text { Survival of } \\
\text { the Fittest }\end{array}$ & $\begin{array}{l}\text { - Populistic trends influence decision-making in many countries. Isolationism } \\
\text { discourages multilateral cooperation on government and business level, } \\
\text { despite continued economic ties in value chains and finance. World } \\
\text { governance institutions decline in influence and supranational bodies see } \\
\text { increased polarisation and drop-outs. } \\
\text { - Conflicts in the Middle East and other parts of the globe intensify. } \\
\text { - The global economy enters a prolonged recession. Energy-related } \\
\text { investments focus on advances in existing (fossil) technologies but do not } \\
\text { spur innovation in renewables and climate engineering. } \\
\text { - Climate policy is at a standstill at the international level, but environmental } \\
\text { - Golicy remains relevant in several countries for health reasons. } \\
\text { - Greenhouse gas emissions escalate, causing an intensification of climate } \\
\text { - With the exception of some localised forces, there is no social momentum } \\
\text { for climate change action, as mitigation objectives are trumped by other } \\
\text { concerns. }\end{array}$ \\
\hline
\end{tabular}




\begin{tabular}{|c|c|}
\hline & $\begin{array}{l}\text { - Energy consumption and production rocket without a major disruption to } \\
\text { today's energy mix. Despite some gains for renewables, the strong increases } \\
\text { in energy consumption are mostly covered by coal and, to a lesser extent, } \\
\text { natural gas. } \\
\text { - Industrial processes see modernisation but rarely switch over to electricity } \\
\text { usage. } \\
\text { - Large, congested centres invest in mass transit systems, but neither a fuel- } \\
\text { switch to electric vehicles nor a decrease of transport demand is visible } \\
\text { outside some localised "green spots". } \\
\text { - Short-term objectives and a focus on domestic stability dominate decision- } \\
\text { making in politics. }\end{array}$ \\
\hline $\begin{array}{l}\text { Green } \\
\text { Cooperation }\end{array}$ & $\begin{array}{l}\text { - Large regional powers are in constant dialogue and cooperate in the context } \\
\text { of an empowered global order. } \\
\text { - Conflicts in the Middle East, South Caucasus, and South China Sea are } \\
\text { settled. } \\
\text { - Multilateral cooperation on all levels is strong, and high investment and } \\
\text { support for R\&D lead to an acceleration of technological progress, } \\
\text { particularly with regards to energy efficiency, renewable energy, storage, } \\
\text { carbon capture and storage as well as various smart technologies that pave } \\
\text { the way for an emission-free world. } \\
\text { - A multitude of multilateral initiatives for curbing emissions is established } \\
\text { and paves the way towards a global carbon price. Climate policy is } \\
\text { integrated with wider economic and social objectives such as poverty } \\
\text { eradication and designed as multilateral, holistic sustainable development } \\
\text { action. } \\
\text { - Prosumers, clean end-user technologies, and decentralised bottom-up } \\
\text { solutions gain importance and enable closing the energy gap in developing } \\
\text { and emerging economies with smart, sustainable solutions, also for urban } \\
\text { areas. } \\
\text { The energy transition moves beyond and creates holistic technological and } \\
\text { societal change towards emission-free modernity. Originating from clean } \\
\text { urban centres in the developed world, the support for climate objectives } \\
\text { spreads quickly and is embraced as a social principle. } \\
\text { Energy-intensive industries are electrified whenever possible or (for the } \\
\text { hardest-to-electrify processes) switch to natural gas. } \\
\text { Energy demand plateaus and electricity generated from renewables takes } \\
\text { over the energy mix. Fossil fuels retreat from the global energy mix, coal } \\
\text { (without CCS) is already phased out by } 2030 \text {. } \\
\text { Long-term considerations become the major force in decision-making and } \\
\text { sustainability is enforced as a hard constraint, which establishes green } \\
\text { growth. }\end{array}$ \\
\hline ClimateTech & $\begin{array}{l}\text { - The current geopolitical scenery persists and so does the international order } \\
\text { despite losing influence prior to a (forced) revival of multilateral governance. } \\
\text { - Promising technological advances in climate and energy engineering take } \\
\text { place early on and attract large investments. However, technology and } \\
\text { energy policy are increasingly seen as a matter of national competition and } \\
\text { ideology, and investments are not focussed multilaterally. } \\
\text { - Emission mitigation slows down in expectation of novel technologies, and } \\
\text { efforts are diverted to other objectives. Cumulative emissions increase } \\
\text { rapidly. } \\
\text { - Societies embrace rapid technological progress and clean technologies, but } \\
\text { climate change mitigation is perceived as an entirely technological issue. }\end{array}$ \\
\hline
\end{tabular}




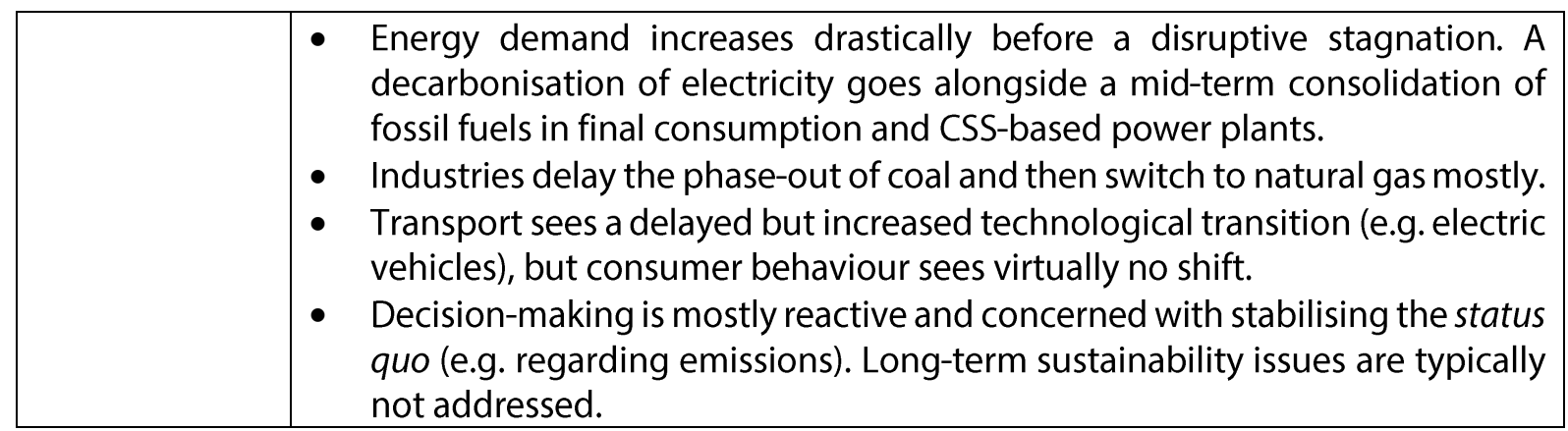

\section{Appendix B. Multimod: Model Setup}

Multimod is an energy and resource market model that reflects the complex, non-linear and interrelated reality of energy infrastructure. We refer to [2] for a detailed description of the model, its purpose, and its relation to other energy models. The model represents the entire supply chain of different energy carriers (both fossil and renewable) in a specially disaggregated framework, as illustrated by Figure 2 .

Similar to other complementarity models and market games, Multimod defines a supply chain of market actors who engage in the production, trading, transformation, transport, and consumption of energy carriers and services. In a nutshell, the model translates detailed information for a base year, reference points for the future, and techno-economic specifications of the supply chain into energy system and market outcomes as the result of an objective-oriented interaction of all market actors. In detail, the model requires disaggregated energy balances for a base year, operational costs for production ${ }^{13}$ and all energy services, investment costs for the expansion of production and energy service capacities as well as their limits ${ }^{14}$, resource reserves, efficiency values, (seasonal) reference demand ${ }^{15}$ values, depreciation rates, and greenhouse gas emission values for each action. The model then computes a single equilibrium solution for all periods, nodes, and actors. This solution contains quantities and flows for production, consumption, conversion, storage, and transport as well as investments into all infrastructures. Additionally, the model determines end-use costs, prices, emissions, and welfare.

The remainder of this section outlines the model's equations (partitioned by the different actors) as well as a brief note on the central updates and changes with respect the model's version in [2].

Table 4 summarises the model's notation.

- Suppliers in each node maximise their profits (1) from the production and sales of fuels, considering their costs for production (2), transportation, transformation, and storage. Their behaviour is restricted by production capacity (3), storage balance (4), production capacity investment limits (5), reserve limits (6), and the nodal mass balance constraint (7). Noticeably, they are the only agent in Multimod that can exercise market power à la Cournot, i.e. they

\footnotetext{
${ }^{13}$ In our formulation, the production (or extraction) of primary energy carriers is modelled with a quadratic cost function, which results in linear but non-constant marginal costs. Hence, two cost production parameters are required for each node and technology.

${ }^{14}$ This includes possibilities for (future) transportation ways such as pipelines on a node-to-node basis but also

15 There is a central difference between having an eventual demand level and a reference demand point as input. Models that use final demand levels as input fix the final quantities exogenously. Hence, such a model is not economic in the sense that the model does not replicate a market action with price and quantity as endogenous variables. In contrast to that, a reference demand point (including a reference price) refers to a single and specific point on the demand curve, which is used to extrapolate the remainder of the curve. Hence, while choosing and varying the reference demand point influences the eventual demand, it does not determine it. This is done endogenously in the interplay of supply and demand.
} 
may not act as price-takers but charge a mark-up on their marginal costs and choose their supply strategically.

$$
\begin{aligned}
& \max _{\substack{q^{p}, q^{A}, q \\
q^{O-}, q^{O+}, q^{D} \\
, z^{P}}} \sum_{\substack{y \in Y, h \in H \\
, n \in N . e \in E}} \delta_{y} d u r_{h}\left(\sum_{d \in D}\left[\operatorname{cour}_{y s n d}^{S} \Pi_{y h n d e}^{D}(\cdot)+\left(1-\operatorname{cour}_{y s n d}^{S}\right) p_{y h s n d e}^{D}\right] q_{y h s n d e}^{D}\right. \\
& -\operatorname{cost}_{\text {yhsne }}^{P}(\cdot) \\
& -\sum_{a \in A_{n e}^{+}} p_{y h a}^{A} q_{y h s a}^{A}-\sum_{c \in C} p_{y h n c e}^{C} q_{y h s n c e}^{C}-\sum_{o \in O_{e}^{E}}\left(p_{y \text { hno }}^{O-} q_{y h s n o}^{O-}+p_{y h n o}^{O+} q_{y h s n o}^{O+}\right) \\
& \left.-\sum_{g \in G} p_{y n g}^{G} e m s_{y s n e g}^{P} q_{y h s n e}^{P}-i n v_{y s n e}^{P} z_{y s n e}^{P}\right)
\end{aligned}
$$

s.t.

$$
\begin{aligned}
& \operatorname{cost}_{y h s n e}^{P}(\cdot)=\operatorname{lin}_{y s n e}^{P} q_{y h s n e}^{p}+q u d_{y s n e}^{P}\left(q_{y h s n e}^{P}\right)^{2} \\
& q_{y h s n e}^{P} \leq a v l_{y h s n e}^{P}\left(\operatorname{cap}_{y s n e}^{P}+\sum_{y^{\prime}<y} d e p_{y^{\prime} y s n e}^{P} z_{y^{\prime} \text { 'sne }}^{P}\right) \\
& \sum_{h \in H_{v o}^{V}} d u r_{h} q_{y h s n o}^{O+}=\sum_{h \in H_{v o}^{V}} d u r_{h}\left(1-\operatorname{loss}_{o}^{O-}\right) q_{y h s n o}^{O-} \\
& \sum_{y \in Y, h \in H} \begin{array}{c}
z_{y s n e}^{P} \leq \exp _{y s n e}^{P} \\
d u r_{h} q_{y h s n e}^{P} \leq \text { hor }_{\text {sne }}^{P}
\end{array} \\
& \left(1-\operatorname{loss}_{\text {sne }}^{P}\right) q_{y h s n e}^{P}-\sum_{d \in D} q_{y h s n d e}^{D} \\
& +\sum_{c \in C, f \in E_{c}^{C-}} \operatorname{trans}_{\text {yncfe }}^{C} q_{y h s n c f}^{C}-\sum_{c \in C} q_{y h s n c e}^{C}+\sum_{a \in A_{n e}^{+}}\left(1-\operatorname{loss}_{a}^{A}\right) q_{y h s a}^{A} \\
& -\sum_{a \in A_{y h s a}^{-}} q_{y h s a}^{A}+\sum_{o \in O_{e}^{E}}\left(q_{y h s n o}^{o+}-q_{y h s n o}^{o-}\right)=0
\end{aligned}
$$

- Transportation agents ('arc operators') operate, by assumptions, each a single arc, i.e. a specific way and mode of transportation between two nodes. They maximise their profits (8) in a competitive market, given capacity restrictions (9), capacity expansion limits (10), and a market-clearing condition (11).

$$
\max _{f^{A}, z^{A}} \sum_{y \in Y, h \in H} \delta_{y} d u r_{h}\left(\left(p_{y h a}^{A}-\operatorname{tr} f_{y a}^{A}\right) f_{y h a}^{A}-\sum_{g \in G} p_{y n g}^{G} e m s_{y a g}^{A} f_{y h a}^{A}-i n v_{y a}^{A} z_{y a}^{A}\right)
$$

s.t.

$$
\begin{gathered}
f_{y h a}^{A} \leq \operatorname{cap}_{y a}^{A}+\sum_{y^{\prime}<y} d e p_{y^{\prime} y a}^{A} z_{y^{\prime} a}^{A} \\
z_{y a}^{A} \leq \exp _{y a}^{A} \\
\sum_{s \in S} q_{y h s a}^{A}=f_{y h a}^{A}
\end{gathered}
$$

- Transformation operators - owners of power plants and refineries - convert primary into secondary energy and are, by assumption, unique in their corresponding nodes (e.g. there is only one refinery operator in China). They maximise their profits (12), given capacity restrictions (13), (policy-enforced) minimum shares of certain input fuels (14), capacity expansion limits (15), and a market-clearing condition (16).

$$
\max _{f^{C}, z^{C}} \sum_{\substack{y \in Y, h \in H, e \in E_{c}^{C-}}} \delta_{y} d u r_{h}\left(\left(p_{y h n c e}^{C}-\operatorname{tr} f_{y n c}^{C}\right) f_{y h n c e}^{C}-\sum_{g \in G} p_{y n g}^{G} e m s_{y c e g}^{C} f_{y h n c e}^{C}-i n v_{y n c}^{C} z_{y n c}^{C}\right)
$$

s.t. 


$$
\begin{aligned}
& \sum_{(e, f) \in E_{c}^{C}} \operatorname{trans} f_{y n c e f}^{C} f_{y h n c e}^{C} \leq c a p_{y n c}^{C}+\sum_{y^{\prime}<y} d e p_{y^{\prime} y n c}^{C} z_{y^{\prime} n c}^{C} \\
& \text { shr } r_{y \text { nce }}^{C} \sum_{(e, f) \in E_{c}^{C}} \text { transf }_{\text {ynce'f }}^{C} f_{\text {yhnce }}^{C} \leq \sum_{f \in E_{c}^{C+}} \text { transf } f_{\text {yncef }}^{C} f_{\text {yhnce }}^{C} \\
& z_{y n c}^{C} \leq \exp _{y n c}^{C} \\
& \sum_{s \in S} q_{y h s n c e}^{C}=f_{y h n c e}^{C}
\end{aligned}
$$

- Storage operators allow to transfer certain energy carriers between seasons. The agents maximise their profits (17), given restrictions of the cumulative energy injections (18) as well as restrictions of the period-wise intake (19) and outtake (20), the corresponding three capacity expansions (21), (22), (23), and market-clearing constraints for energy in- and outtake (24), (25).

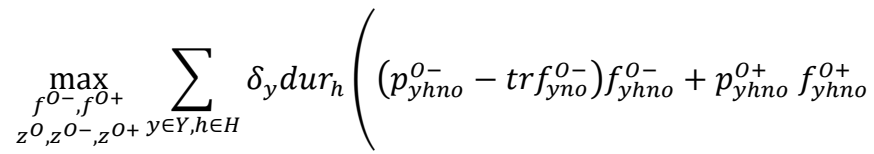

$$
\begin{aligned}
& \left.-\sum_{g \in G} p_{y n g}^{G} e m s_{y o g}^{O-} f_{y h n o}^{O-}-i n v_{y n o}^{O} z_{y n o}^{O}-i n v_{y n o}^{O-} z_{y n o}^{O-}-i n v_{y n o}^{O+} z_{y n o}^{O+}\right)
\end{aligned}
$$

s.t.

$$
\begin{aligned}
& \sum_{h \in H_{v o}^{V}} d u r_{h} f_{y h n o}^{O-} \leq c a p_{y n o}^{O}+\sum_{y^{\prime}<y} d e p_{y^{\prime} y n o}^{O} z_{y^{n} n o}^{O} \\
& f_{\text {yhno }}^{O-} \leq \operatorname{cap}_{\text {yno }}^{O-}+\sum_{y^{\prime}<y} \operatorname{dep}_{y^{\prime} y n o}^{O-} z_{y^{n} \text { no }}^{O-} \\
& f_{y h n o}^{O+} \leq \operatorname{cap}_{y n o}^{O+}+\sum_{y^{\prime}<y} \operatorname{dep}_{y^{\prime} y n o}^{O+} z_{y^{\prime} n o}^{O+} \\
& z_{y \text { yno }}^{O} \leq \exp _{\text {yno }}^{O} ; z_{\text {yno }}^{O-} \leq \exp _{\text {yno }}^{O-} ; z_{y \text { no }}^{O+} \leq \exp _{\text {yno }}^{O+} \\
& \sum_{s \in S} q_{y h s n o}^{O-}=f_{\text {yhno }}^{O-} ; \sum_{s \in S} q_{y h s n o}^{O+}=f_{\text {yhno }}^{O+}
\end{aligned}
$$

- Emission authorities auction emission permits in a profit-maximising ${ }^{16}$ way (26) based on national (27), regional (28), or global (29), greenhouse gas quotas. (30) is the global market clearing condition, including emissions from production, consumption, and all energy services.

s.t.

$$
\max _{f^{C}} \sum_{\substack{y \in Y, n \in N \\ g \in G}} \delta_{y}\left(p_{y n g}^{G}-\operatorname{tax}_{y g}^{g l o b}-\sum_{r \in R_{n}} \operatorname{tax}_{y r g}^{r e g}-\operatorname{tax}_{y \text { yng }}^{\text {nod }}\right) f_{y n g}^{G}
$$

$$
\begin{aligned}
\sum_{n \in N} f_{y n g}^{G} & \leq q u o t a_{y g}^{g l o b}+\sum_{n \in N} z_{y n g}^{G} \\
\sum_{n \in N_{r}} f_{y n g}^{G} & \leq q u o t a_{y r g}^{r e g}+\sum_{n \in N_{r}}^{n} z_{y n g}^{G} \\
f_{y n g}^{G} & \leq q u o t a_{y n g}^{n o d}+z_{y n g}^{G}
\end{aligned}
$$

\footnotetext{
${ }^{16}$ Although the authority is a public entity without the objective to maximise profits, it is formally easier to introduce them as profit maximisers too. Given the First Theorem of Welfare Economics, the solution of a perfectly competitive market with profit-maximising agents equals the welfare-optimal allocation, which is why these two perspectives do not differ in terms of model results.
} 


$$
\begin{gathered}
\sum_{h \in H, e \in E} d u r_{h}\left(\sum_{s \in S} e m s_{y s n e g}^{P} q_{y h s n e}^{P}+\sum_{s \in S, d \in D} e m s_{y d e g}^{D} q_{y h s n d e}^{D}+\sum_{a \in A_{n e}^{+}} e m s_{y a g}^{A} f_{y h a}^{A}\right. \\
\left.+\sum_{c \in C} e m s_{y c e g}^{C} f_{\text {ynnce }}^{C}+\sum_{o \in O} e m s_{\text {yog }}^{O-} f_{y h n o}^{O-}\right)=f_{y n g}^{G}
\end{gathered}
$$

- Consumers that represent the different demand sectors in each node are utility-maximising agents gaining utility from the consumption of energy and weighing it against $\backslash$ emission, end-use, and fuel costs. The result of the utility maximisation manifests in the demand function (31). The end-use costs are automatically calibrated by auxiliary algorithms of Multimod and mimic endogenous fuel substitution, as elaborated in the appendix of [2].

$$
\begin{aligned}
p_{y h n d e}^{D}=e f f_{\text {ynde }}^{D} & {\left[i n t_{y h n d}^{D}-s p_{y h n d}^{D}\left(\sum_{s \in S, f \in E} e f f_{y n d f}^{D} q_{y h s n d f}^{D}\right)\right]-e u c c_{y h n d e}^{D} } \\
& - \text { eucc c } c_{y n n d e}^{D}\left(\sum_{S \in S} q_{y h s n d e}^{D}\right)-\sum_{g \in G} p_{y n g}^{G} e m s_{y d e g}^{D}
\end{aligned}
$$

In contrast to the model outlined in [2], we augmented the model in three ways. First, to improve tractability and numerical behaviour of the model, we removed the logarithmic term of the production cost function and reduced it to a quadratic function. Secondly, we added investments into negative emission technologies $z_{y n g}^{G}$ as a choice variable that enters emission constraints. ${ }^{17}$ Lastly, and most importantly, we reformulated the model - originally a mixed complementarity problem (MCP) - into a convex quadratic optimisation problem.

To realise this, we are to the best of our knowledge the first major application of the method described by [41]. The original MCP is given by the Karush-Kuhn-Tucker conditions of the problems derived from (1)-(31), i.e. the set of first order conditions to the Lagrangians of all agents. Given the size of our dataset, however, this MCP requires more than three days to solve on a modern computer, which makes the calibration of the model nearly infeasible. Therefore, we convexified the model into a quadratically constrained program (QCP) ${ }^{18}$. The $\mathrm{QCP}^{\prime} \mathrm{s}$ objective function is given as the multivariable antiderivative of the entire set of stationarity conditions of the MCP. This antiderivative (32) can be understood as the scalar potential to the vector field that is defined by the first-order derivatives of each agent's objective functions, which can be shown to exist in this case due to the linearity of (inverse) demand and the convexity of the feasible area.

Hence, the final model for this study is given by the maximisation (32) under the restrictions (2) - (7), (9) - (11), (13) - (16), (18) - (25), and (27) - (31). The model is implemented in the algebraic modelling language GAMS and solved using the commercial solver CPLEX.

\footnotetext{
${ }^{17}$ We only make use of this feature in the Climate Tech scenario, which features investment costs and investment limits exogenously fixed. In all other scenarios, this option is ruled out.

${ }^{18} \mathrm{~A}$ sketch of the proof for the equivalence of the MCP and the QCP version can be found in [42] R. Egging, D. Ansari, An introductory tutorial on convex formulations for equilibrium and bi-level problems, SET-Nav Discussion Paper (2019).
} 


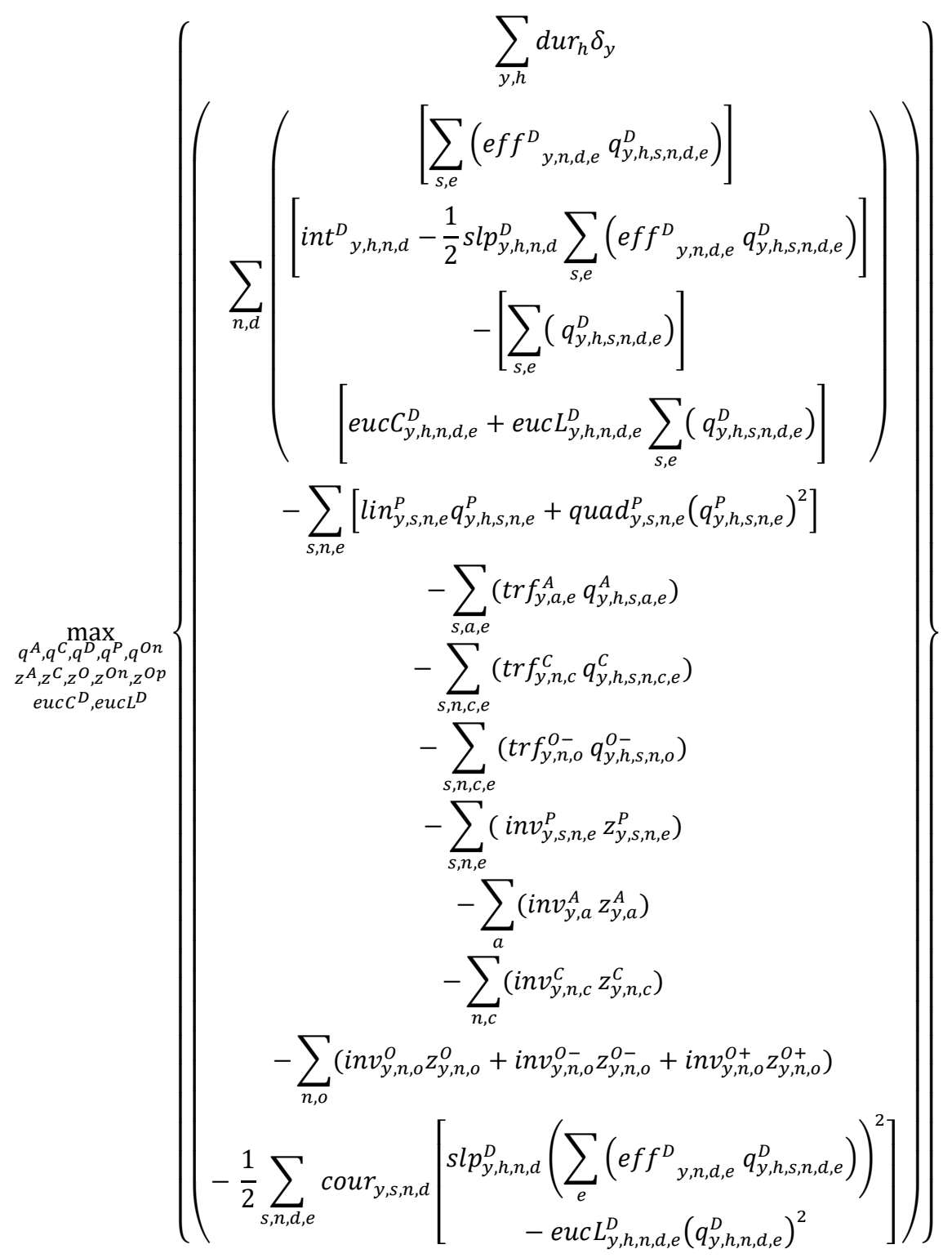


Table 4: List of sets, parameters, variables, and mappings in Multimod

\begin{tabular}{|c|c|c|c|}
\hline Symbol & Description & Symbol & Description \\
\hline \multicolumn{4}{|l|}{ Sets } \\
\hline$y \in Y$ & years & $a \in A$ & $\operatorname{arcs}$ \\
\hline$h \in H$ & seasons & $c \in C$ & transformation technology \\
\hline$s \in S$ & suppliers & $e, f \in E$ & energy carriers/fuels \\
\hline$n, k \in N$ & nodes & $r \in R$ & regions \\
\hline$d \in D$ & demand sectors & $g \in G$ & emission types \\
\hline$l \in L$ & sector fuel mix constraints & $o \in O$ & storage operators/technology \\
\hline$m \in M$ & transformation mix constraints & $v \in V$ & loading cycles of storage \\
\hline \multicolumn{4}{|c|}{ Parameters and functions } \\
\hline$d u r_{h}$ & $\begin{array}{l}\text { relative duration of season } h \text { (with } \sum_{h} d u r_{h}= \\
\text { 1) }\end{array}$ & $\operatorname{cap}_{(\cdot)}^{(\cdot)}$ & service or production capacity \\
\hline $\exp _{(\cdot)}^{(\cdot)}$ & capacity expansion limit & $\operatorname{inv}(\cdot)$ & unit cost of capacity expansion \\
\hline $\operatorname{tr} f_{(\cdot)}^{(\cdot)}$ & unit cost for service provision & $\operatorname{dep}_{(\cdot)}^{(\cdot)}$ & Infrastructure depreciation rate \\
\hline & relative losses though service usage & $e m s_{(\cdot)}^{(\cdot)}$ & unit emissions \\
\hline $\operatorname{cost}_{\text {yhsne }}^{P}(\cdot)$ & production cost function & hor $r_{\text {sne }}^{P}$ & production horizon (reserves) \\
\hline $\operatorname{lin}_{y s n e}^{P}$ & $\begin{array}{l}\text { linear term of the production cost function } \\
\left(\operatorname{lin}^{P} \geq 0\right)\end{array}$ & $\operatorname{trans} f_{\text {yncef }}^{C}$ & $\begin{array}{l}\text { transformation rate by technology } c \text { at node } n \\
\text { from input } e \text { to output } f\end{array}$ \\
\hline$q u d_{y s n e}^{P}$ & $\begin{array}{l}\text { quadratic term of the production cost } \\
\text { function }\left(q u d^{P} \geq 0\right)\end{array}$ & $s h r_{y n c e}^{C}$ & $\begin{array}{l}\text { minimum share of (input) fuel } e \text { by } \\
\text { transformation technology } c\end{array}$ \\
\hline $\operatorname{cour}_{y s n d}^{S}$ & Cournot market power parameter & $\operatorname{quota}_{(\cdot)}^{(\cdot)}$ & quota for nodal / regional / global emissions \\
\hline$a v l_{y h s n e}^{P}$ & availability factor of production capacity & $e f f_{y n d e}^{D}$ & $\begin{array}{l}\text { efficiency of demand satisfaction of sector } d \text { by } \\
\text { fuel } e \text { at node } n\end{array}$ \\
\hline$\Pi_{\text {yhnde }}^{D}(\cdot)$ & inverse demand curve of sector $d$ & eucl $l_{\text {yhnde }}^{D}$ & linear end use cost parameter \\
\hline$i n t_{y h n d}^{D}$ & $\begin{array}{l}\text { intercept of inverse demand curve for fuel } e \text { at } \\
\text { node } n\end{array}$ & eucc $c_{y h n d e}^{D}$ & constant end use cost parameter \\
\hline$s l p_{y h n d}^{D}$ & $\begin{array}{l}\text { slope of inverse demand curve for fuel } e \text { at } \\
\text { node } n\end{array}$ & $s h r_{y n l}^{(\cdot)}$ & $\begin{array}{l}\text { minimum share of sector fuel mix constraint } l \\
\text { (in energy services) }\end{array}$ \\
\hline$\delta_{y}$ & discount factor & & \\
\hline \multicolumn{4}{|l|}{ Variables } \\
\hline$q_{(\cdot)}^{(\cdot)}$ & $\begin{array}{l}\text { quantity produced / sold / interacting with } \\
\text { service }\end{array}$ & $p_{(\cdot)}^{(\cdot)}$ & market-clearing price of fuel or service \\
\hline$f_{(\cdot)}^{(\cdot)}$ & flow of energy or emissions & $z_{(\cdot)}^{(\cdot)}$ & capacity expansion \\
\hline \multicolumn{4}{|l|}{ Mappings } \\
\hline $\begin{array}{l}n, k \in N_{r} \\
r \in R_{n} \\
a \in A_{n e}^{+}\end{array}$ & $\begin{array}{l}\text { node-to-region mapping } \\
\text { region-to-node mapping } \\
\text { subset of arcs ending at node } n \text { transporting } \\
\text { fuel } e\end{array}$ & $\begin{array}{l}e^{O}(o) \\
o \in O_{e}^{E} \\
h \in H_{v o}^{V}\end{array}$ & $\begin{array}{l}\text { fuel stored by technology } o \\
\text { subset of technologies storing fuel } e \\
\text { mapping between loading cycle and } \\
\text { hour/day/season }\end{array}$ \\
\hline$a \in A_{n e}^{-}$ & $\begin{array}{l}\text { subset of arcs starting at node } n \text { transporting } \\
\text { fuel } e\end{array}$ & $v^{H}(h, o)$ & loading cycle of hour/day/season (singleton) \\
\hline $\begin{array}{l}e \in E_{a}^{A} \\
n^{A+}(a)\end{array}$ & $\begin{array}{l}\text { fuel(s) transported via arc } a \text { (singleton) } \\
\text { end node of arc } a\end{array}$ & $\begin{array}{l}e \in E_{l}^{L} \\
e \in \hat{E}^{L}\end{array}$ & $\begin{array}{l}\text { fuel(s) that satisfies fuel mix constraint } l \\
\text { fuel }(\mathrm{s}) \text { that are included in fuel mix constraint } l\end{array}$ \\
\hline$n^{A-}(a)$ & start node of $\operatorname{arc} a$ & $\begin{array}{l}e \in E_{l} \\
e \in E_{m}^{M}\end{array}$ & $\begin{array}{l}\text { fuel(s) that are Included in fuel mix constraint } l \\
\text { fuel(s) that satisfies transformation mix } \\
\text { constraint } m\end{array}$ \\
\hline$f \in E_{c}^{C+}$ & $\begin{array}{l}\text { subset of output fuel(s) } f \text { obtained from } \\
\text { transformation technology } c\end{array}$ & $d \in D_{l}^{L}$ & $\begin{array}{l}\text { demand sector(s) to which fuel mix constraint } l \\
\text { applies }\end{array}$ \\
\hline$e \in E_{c}^{C-}$ & $\begin{array}{l}\text { subset of input fuel(s) } e \text { for transformation } \\
\text { technology } c\end{array}$ & $c \in C_{m}^{M}$ & $\begin{array}{l}\text { transformation technologies that satisfy } \\
\text { transformation mix constraint } m\end{array}$ \\
\hline$(e, f) \in E_{c}^{C}$ & $\begin{array}{l}\text { input/output fuel mapping of transformation } \\
\text { technology } c\end{array}$ & & \\
\hline
\end{tabular}




\section{Appendix C. Multimod: Input data}

The calibration of Multimod uses a dataset named 30 nodes plus, which is an extended and updated version of the dataset used in [2], to which refer for a general and more comprehensive overview regarding structure and data sources.

The setup covers natural gas, coall ${ }^{19}$, lignite, and crude oil on the fossil fuel side as well as hydro, biofuels ${ }^{20}$ and other renewables (solar / wind / geothermal), and nuclear energy on the upstream level. Demand sectors can use certain primary fuels directly, or they can be transformed into processed energy carriers (electricity from all fuels and oil products from crude oil). Also, transportation is possible via multiple pre-defined ways of transportation (ship, pipeline, rail, street, powerline), depending on fuel and node. Natural gas can also be liquefied to and regasified from LNG. Market power - modelled via conjectural variation in asymmetric competition in quantities under perfect foresight - is assumed for a limited number of oil and gas producers (OPEC members, Qatar, Russia).

Sectoral data (e.g. costs, capacities, reserves, processing and distribution infrastructure) is taken from recent scientific publications and DIW Berlin data documentations, in particular [43] for natural gas, [44] for coal, [39] for oil, [40] for CCS, and [45, 46] for electricity and renewables. This includes data on emissions, which are specified for different fuels and actions (i.e. the model accounts for emissions at each point of the value chain). Additionally, we rely on outcomes of the Re-shaping ${ }^{21}$ project for renewables and data from British Petroleum and the Oil and Gas Journal for the oil sector.

Regarding demand, the model distinguishes three separate and individual sectors (residential, industrial, transportation), which are represented by an own demand in each node. Multimod requires reference demand ${ }^{22}$ values for each node, sector, and period, which are central to the model's automatic calibration and work as key parameters for calibrating the different scenarios. For the year 2015, fixed demand values are taken from [34]. Regarding future periods (i.e. 2025, 2035, $2045,2055)$, we derive base line demand values from the numerical results of [36] ${ }^{23}$ and process them into growth rates per decade. Then, we alter and differentiate these growth rates to reflect the four storylines. The final reference demand values for future periods are then obtained by multiplying the corresponding growth rates with the (fixed) base year demand.

The four scenarios vary along several parameters that are chosen to mimic the settings and series of events of the storylines. As elaborated above, this includes especially reference demand values, but also the availability and costs of (new) transportation ways (e.g. in Survival of the Fittest, increased geopolitical tensions and isolationism turn most multilateral pipeline projects infeasible, while numerous new transportation ways are open to investment in Green Cooperation). Of course, climate policies vary largely between the scenarios; for reasons of smoothness of calibration, in all scenarios, they were modelled as emission caps $^{24}$. Another set of parameters fitted to the storylines centres around technological development and its consequences. All scenarios feature cost degressions and efficiency increases, but their extent and focus differ: Business as Usual sees modest developments in all technologies; Survival of the fittest sees the lowest advances in renewables but efficiency gains for conventional power plants as well as the production and availability of fossils; Green Cooperation sees strong improvements in the availability, costs, and efficiencies of

\footnotetext{
${ }^{19} \mathrm{Coal}$ refers to the sum of hard coal and lignite consumption and the quantity-weighted average, respectively, in line with IEA and BP reports.

${ }^{20}$ Biofuels are defined according to [34] International Energy Agency, Extended world energy balances (2017).and cover both primitive biomass as well as processed biofuels.

${ }^{21}$ See https://www.reshaping-res-policy.eu/

${ }^{22}$ See footnote 15.

${ }^{23}$ The MIT Joint Program on the Science and Policy of Global Change and provides an independent forecast for primary energy use and electricity production as well as generation mix.

${ }^{24}$ Since the model assumes perfect foresight and common knowledge, there is no difference between the effect of a tax or a cap.
} 
renewables as well as CCS; ClimateTech shows strong developments in all technologies in addition to (increasingly available and affordable) negative emission technologies as well as nuclear fusion.

\section{References}

[1] M.J. Burrows, O.J.F. Gnad, Between 'muddling through'and 'grand design': Regaining political initiative-The role of strategic foresight, Futures 97 (2018) 6-17.

[2] D. Huppmann, R. Egging, Market power, fuel substitution and infrastructure-A large-scale equilibrium model of global energy markets, Energy 75 (2014) 483-500.

[3] C.A. Miller, J. Richter, J. O'Leary, Socio-energy systems design: a policy framework for energy transitions, Energy Research \& Social Science 6 (2015) 29-40.

[4] J.A. Alic, D. Sarewitz, Rethinking innovation for decarbonizing energy systems, Energy Research \& Social Science 21 (2016) 212-221.

[5] E. Noboa, P. Upham, Energy policy and transdisciplinary transition management arenas in illiberal democracies: a conceptual framework, Energy Research \& Social Science 46 (2018) 114-124.

[6] D.K.J. Schubert, S. Thuss, D. Möst, Does political and social feasibility matter in energy scenarios?, Energy Research \& Social Science 7 (2015) 43-54.

[7] G. Carrington, J. Stephenson, The politics of energy scenarios: Are International Energy Agency and other conservative projections hampering the renewable energy transition?, Energy Research \& Social Science 46 (2018) 103-113.

[8] M. Sharmina, D.A. Ghanem, A.L. Browne, S.M. Hall, J. Mylan, S. Petrova, R. Wood, Envisioning surprises: How social sciences could help models represent 'deep uncertainty'in future energy and water demand, Energy Research \& Social Science 50 (2019) 18-28.

[9] S. Pye, F.G. Li, A. Petersen, O. Broad, W. McDowall, J. Price, W. Usher, Assessing qualitative and quantitative dimensions of uncertainty in energy modelling for policy support in the United Kingdom, Energy Research \& Social Science 46 (2018) 332-344.

[10] F.W. Geels, F. Berkhout, D.P. van Vuuren, Bridging analytical approaches for low-carbon transitions, Nature Climate Change 6(6) (2016) 576.

[11] B. Turnheim, F. Berkhout, F. Geels, A. Hof, A. McMeekin, B. Nykvist, D. van Vuuren, Evaluating sustainability transitions pathways: Bridging analytical approaches to address governance challenges, Global Environmental Change 35 (2015) 239-253.

[12] S. Pfenninger, A. Hawkes, J. Keirstead, Energy systems modeling for twenty-first century energy challenges, Renewable and Sustainable Energy Reviews 33 (2014) 74-86.

[13] C. Rachmatullah, L. Aye, R.J. Fuller, Scenario planning for the electricity generation in Indonesia, Energy Policy 35(4) (2007) 2352-2359.

[14] R. Ghanadan, J.G. Koomey, Using energy scenarios to explore alternative energy pathways in California, Energy Policy 33(9) (2005) 1117-1142.

[15] S. Chaharsooghi, M. Rezaei, M. Alipour, Iran's energy scenarios on a 20-year vision, International journal of Environmental Science and Technology 12(11) (2015) 3701-3718.

[16] W. McDowall, Exploring possible transition pathways for hydrogen energy: a hybrid approach using socio-technical scenarios and energy system modelling, Futures 63 (2014) 1-14.

[17] J. Anable, C. Brand, M. Tran, N. Eyre, Modelling transport energy demand: A socio-technical approach, Energy Policy 41 (2012) 125-138.

[18] D. MacKay, Sustainable Energy-without the hot air, UIT Cambridge2008.

[19] S. Pacala, R. Socolow, Stabilization wedges: solving the climate problem for the next 50 years with current technologies, Science 305(5686) (2004) 968-972.

[20] V.R. Mallampalli, G. Mavrommati, J. Thompson, M. Duveneck, S. Meyer, A. Ligmann-Zielinska, C.G. Druschke, K. Hychka, M.A. Kenney, K. Kok, Methods for translating narrative scenarios into quantitative assessments of land use change, Environmental Modelling \& Software 82 (2016) 7-20.

[21] E.A. Moallemi, S. Malekpour, A participatory exploratory modelling approach for long-term planning in energy transitions, Energy Research \& Social Science 35 (2018) 205-216.

[22] J. Alcamo, Chapter six the SAS approach: combining qualitative and quantitative knowledge in environmental scenarios, Developments in integrated environmental assessment 2 (2008) 123-150. 
[23] W. Weimer-Jehle, J. Buchgeister, W. Hauser, H. Kosow, T. Naegler, W.-R. Poganietz, T. Pregger, S. Prehofer, A. von Recklinghausen, J. Schippl, Context scenarios and their usage for the construction of socio-technical energy scenarios, Energy 111 (2016) 956-970.

[24] L. Braunreiter, Y.B. Blumer, Of sailors and divers: How researchers use energy scenarios, Energy Research \& Social Science 40 (2018) 118-126.

[25] F. Holz, P. Richter, R. Egging, A Global Perspective on the Future of Natural Gas: Resources, Trade, and Climate Constraints, Review of Environmental Economics Policy 9(1) (2015) 85-106.

[26] International Energy Agency, World Energy Outlook 2018, 2018.

[27] R.J. Heuer, R.H. Pherson, Structured Analytic Techniques for Intelligence Analysis, Second edition ed., SAGE Publications, London, United Kingdom, 2015.

[28] K.H. Pherson, R.H. Pherson, Critical thinking for strategic intelligence, SAGE Publications, Washington, United States, 2016.

[29] D. Ansari, F. Holz, N. Appleman, SET-Nav Case Study Report: Scenarios of the global fossil fuel markets, 2018.

[30] L. Langer, D. Huppmann, F. Holz, Lifting the US crude oil export ban: A numerical partial equilibrium analysis, Energy Policy 97 (2016) 258-266.

[31] O. Oke, D. Huppmann, M. Marshall, R. Poulton, S. Siddiqui, Multimodal Transportation Flows in Energy Networks with an Application to Crude Oil Markets, Networks and Spatial Economics (2018) 1-35.

[32] S. Sankaranarayanan, F. Feijoo, S. Siddiqui, Sensitivity and covariance in stochastic complementarity problems with an application to North American natural gas markets, European Journal of Operational Research 268(1) (2017) 25-32.

[33] C. Bakker, B.F. Zaitchik, S. Siddiqui, B.F. Hobbs, E. Broaddus, R.A. Neff, J. Haskett, C.L. Parker, Shocks, seasonality, and disaggregation: Modelling food security through the integration of agricultural, transportation, and economic systems, Agricultural Systems 164 (2018) 165-184.

[34] International Energy Agency, Extended world energy balances (2017).

[35] R.G. Prinn, Development and application of earth system models, Proceedings of the National Academy of Sciences 110(Supplement 1) (2013) 3673-3680.

[36] Y. Chen, Q. Ejaz, X. Gao, J. Huang, J. Morris, E. Monier, S. Patsev, J. Reilly, A. Schlosser, J. Scott, Food, water, energy and climate outlook: Perspectives from 2016, MIT Joint Program on the Science and Policy of Global Change. (http://globalchange.mit.edu/Outlook2016), 2016.

[37] Y.-H. Chen, S. Paltsev, J.M. Reilly, J.F. Morris, M.H. Babiker, The MIT EPPA6 model: Economic growth, energy use, and food consumption, MIT Joint Program on the Science and Policy of Global Change, 2015.

[38] F. Holz, P.M. Richter, R. Egging, The Role of Natural Gas in a Low-Carbon Europe: Infrastructure and Supply Security, Energy Journal 37 (2016).

[39] D. Ansari, OPEC, Saudi Arabia, and the shale revolution: Insights from equilibrium modelling and oil politics, Energy Policy 111 (2017) 166-178.

[40] P.-Y. Oei, R. Mendelevitch, European scenarios of CO2 infrastructure investment until 2050, The Energy Journal 37 (2016).

[41] T. Baltensperger, R. Egging, A. Tomasgard Solving imperfect market equilibrium problems with convex optimization, CenSES working paper (1/2018) (2018).

[42] R. Egging, D. Ansari, An introductory tutorial on convex formulations for equilibrium and bi-level problems, SET-Nav Discussion Paper (2019).

[43] R. Egging, F. Holz, Risks in global natural gas markets: investment, hedging and trade, Energy Policy 94 (2016) 468-479.

[44] F. Holz, C. Haftendorn, R. Mendelevitch, C. von Hirschhausen, DIW Berlin: a model of the international Steam Coal Market (COALMOD-World). DIW Data Documentation 85. DIW Berlin, Berlin, 2016.

[45] K. Löffler, K. Hainsch, T. Burandt, P.-Y. Oei, C. Kemfert, C.J.E. von Hirschhausen, Designing a Model for the Glogbal Energy System-GENeSYS-MOD: An Application of the Open-Source Energy Modeling System (OSeMOSYS), 10(10) (2017) 1468.

[46] C. Gerbaulet, C. Lorenz, dynELMOD: A dynamic investment and dispatch model for the future european electricity market, Data Documentation, DIW, 2017. 